\title{
PATZ1 is a new prognostic marker of glioblastoma associated with the stem-like phenotype and enriched in the proneural subtype
}

\author{
Elia Guadagno${ }^{1}$, Michela Vitiello², Paola Francesca², Gaetano Calìn${ }^{2}$, Federica \\ Caponnetto $^{3}$, Daniela Cesselli ${ }^{3}$, Simona Camorani ${ }^{2}$, Giorgio Borrelli' ${ }^{1}$, Marialuisa \\ Califano ${ }^{1}$, Paolo Cappabianca ${ }^{4}$, Claudio Arra ${ }^{5}$, Elvira Crescenzi², Laura Cerchia ${ }^{2}$, \\ Maria Laura Del Basso De Caro ${ }^{1}$ and Monica Fedele ${ }^{2}$

\footnotetext{
${ }^{1}$ Department of Advanced Biomedical Sciences, Pathology Section, University of Naples Federico II, 80131 Naples, Italy

${ }^{2}$ Institute of Experimental Endocrinology and Oncology (IEOS) "Gaetano Salvatore", National Council of Research, 80131 Naples, Italy

${ }^{3}$ Department of Medical and Biological Sciences, University of Udine, 33100 Udine, Italy

${ }^{4}$ Division of Neurosurgery, Department of Neurosciences, Reproductive and Odontostomatological Sciences, University of Naples Federico II, 80131 Naples, Italy

${ }^{5}$ Department of Experimental Oncology, National Cancer Institute "Fondazione Giovanni Pascale", IRCCS, 80131 Naples, Italy

Correspondence to: Monica Fedele, email: mfedele@unina.it, monica.fedele@cnr.it
}

Maria Laura Del Basso De Caro, email: marialaura.delbasso@unina.it

Keywords: glioma, glioma stem cells, PATZ1, tumor heterogeneity, biomarker

Received: January 18, $2017 \quad$ Accepted: June 19, $2017 \quad$ Published: July 25, 2017

Copyright: Guadagno et al. This is an open-access article distributed under the terms of the Creative Commons Attribution License 3.0 (CC BY 3.0), which permits unrestricted use, distribution, and reproduction in any medium, provided the original author and source are credited.

\section{ABSTRACT}

Glioblastoma (GBM), the most malignant of the brain tumors, has been classified on the basis of molecular signature into four subtypes: classical, mesenchymal, proneural and neural, among which the mesenchymal and proneural subtypes have the shortest and longest survival, respectively. Here we show that the transcription factor PATZ1 gene is upregulated in gliomas compared to normal brain and, among GBMs, is particularly enriched in the proneural subtype and co-localize with stemness markers. Accordingly, in GBM-derived glioma-initiating stem cells (GSCs) PATZ1 is overexpressed compared to differentiated tumor cells and its expression significantly correlates with the characteristic stem cell capacity to grow as neurospheres in vitro. Interestingly, survival analysis demonstrated that PATZ1 lower levels informed poor prognosis in GBM and, specifically, in the proneural subgroup, suggesting it may serve a role as diagnostic and prognostic biomarker for intra-subtype heterogeneity of proneural GBM. We also show that PATZ1 suppresses the expression of the mesenchyme-inducer CXCR4, and that PATZ1 and CXCR4 are inversely correlated in GSC and proneural GBM. Overall these findings support a central role of PATZ1 in regulating malignancy of GBM.

\section{INTRODUCTION}

Glioblastoma (GBM) is the most frequent primary malignant brain tumor and is one of the most aggressive neoplasms among the human cancers [1]. It is characterized by dismal prognosis with median survival of 16-19 months despite multimodal treatment including surgical resection followed by combined radiochemotherapy [2]. In spite of enormous efforts towards understanding the molecular basis of the disease and the development of novel therapeutic strategies, only limited advances have been achieved and there is a pressing need to identify proteins and signalling pathways that can serve as new targets for an improved treatment of GBM. The identification of brain tumour 
stem-like cells [3], in both adult and pediatric malignant gliomas, has provided new insights into the biology of malignant glial tumours rendering these cells a potentially valuable therapeutic target. Indeed, a major drawback in the treatment of GBM is its resistance against standard therapeutic approaches, and current data attribute the resistance against both $\gamma$-irradiation and chemotherapeutic alkylating agent Temozolomide to the cancer stem cells [4]. Therefore, therapeutic targets in glioma-initiating stem cells (GSCc) are a focus of increasing interest to improve the GBM outcome.

Systematic gene expression and sequencing of GBM (WHO grade IV gliomas) have revealed a great heterogeneity of this disease with at least two major tumor subgroups (proneural and mesenchymal) and two other intermediate possible groups (classical/proliferative and neural) [5-7]. Among them, the proneural subtype is characterized by a stem-like signature and cells with a full stem phenotype [8], TP53 mutations and unresponsiveness to aggressive chemo- and radio- treatments [7].

All normal tissues host a small population of stem cells. These are "initiating cells' with the unique ability to proliferate and differentiate into a variety of other cells depending on the tissue in which they are located in the body. In the brain, neogenesis of mature cells persists throughout adult life within discrete regions, primarily in the dentate gyrus of the hippocampus and in the subventricular zone of the forebrain lateral ventricles. The emerging hypothesis is that alterations in the cellular and genetic mechanisms that control adult neurogenesis might contribute to brain tumorigenesis. The main implication of continued adult neurogenesis is the presence of undifferentiated, mitotically active stem and progenitor cells within discrete regions of the mature brain. These populations might function as a source of cells for transformation, giving rise to GSCs [9]. Despite the stem cell population within a tumour represents a minor subpopulation (only $2 \%$ of cancer cells), it is responsible for tumor maintenance and progression, and it phenocopies the original tumour in rodent xenograft models. Depletion of the cancer stem cell population greatly impairs the potential of the bulk tumours to initiate xenograft tumour formation and leads to prolonged survival of tumour-bearing mice [10]. While the suitability of GSCs as therapeutic targets has been recently validated in vivo [11], the molecular signalling pathways orchestrating the biology of GSCs, as well as of the other cancer stem cells, remain to be elucidated.

It has been recently shown that the $\mathrm{C} 2 \mathrm{H} 2$ zinc finger protein PATZ1 (POZ, AT-hook and Zinc-finger 1) is an important regulator of pluripotency in embryonic stem cells, directly involved in the regulation of pluripotency master genes, such as Pou5f1 and Nanog, which together with Sox2 are necessary for maintaining self renewal and pluripotency [12]. A PATZ1 role in neural stem cells has also been suggested by our previous studies showing it is highly expressed in actively proliferating neuroblasts of the periventricular and subventricular neocortical neuroepithelium, and Patz1-knockout mice have proliferative defects of the subventricular zone [13]. PATZ1 is a member of the POK (POZ and kruppel-like zinc finger) family, a unique group of transcription factors playing key roles in development and cancer through their involvement in a variety of cellular processes, including cell proliferation, senescence and apoptosis [14]. PATZ1 itself has been implicated in all these processes [13, 15-20]. In addition, several studies indicate a role of PATZ1 in carcinogenesis, sometimes working as a tumour suppressor and sometimes as an oncogene, depending on the cellular context [16-23]. In human brain tumour cells PATZ1 has been found to be included in the SOX2-interactome [24], and targeting of PATZ1 by siRNA in human GBM cell lines resistant to conventional chemotherapy, increases their sensitivity to apoptotic stimuli [17].

Here we characterized the expression of PATZ1 in human gliomas showing it is overexpressed compared to normal brain and is significantly enriched in the proneural GBM subtype, where it behaves as a valuable prognostic marker. We also show that PATZ1 protein in GBM colocalizes with stem cell markers, is increased in GBMderived stem cells compared with tumor differentiated cells, and correlates with the capacity of these cells to grow as spheres. Finally, we show that in GBM and GBMderived cells PATZ1 expression negatively correlates with the expression of the G-protein coupled receptor and mesenchyme inducer CXCR4, suggesting a role of PATZ1 in suppressing the mesenchymal subtype.

\section{RESULTS}

\section{PATZ1 is expressed in human gliomas and is enriched in the proneural subtype}

Using paraffin embedded sections generated from surgical specimens collected at the Department of Advanced Biomedical Sciences, Pathology Section, of the University of Naples Federico II, we analysed by immunohistochemistry PATZ1 expression in 45 grade IV GBM, 22 oligodendrogliomas (10 grade III and 12 grade II) and 26 perilesional normal brain parenchymas. Of 45 GBM patients included in the study, 30 were males and 15 females, aged between 26 and 81 years. The lesion was mainly localized in the temporal lobe in 22 cases, parietal in 11 cases, frontal in 9 cases, occipital in 2 cases and 1 in the corpus callosum (Supplementary Table 1). Of 22 oligodendroglioma patients 15 were males and 7 females, aging from 22 to 69 years. 14 cases were frontal, 4 temporal, 3 occipital and 1 was an intramedullary metastasis (Supplementary Table 2).

We have observed that PATZ1 protein is expressed in neurons (mainly in the nucleus) but not in glial cells of all perilesional normal brain tissues (Figure 1A), whereas it is expressed in a high percentage of GBM $(69 \%)$ with a main 
nuclear, but sometimes cytoplasmic localization (Figure 1B, Supplementary Table 1) and oligodendrogliomas (54\%) (Supplementary Table 2). Among positive samples, PATZ1 immunoreactivity was variable in both GBM and oligodendrogliomas, including samples scored $+(\leq 10 \%)$, $++(>10 \%<50 \%),+++(\geq 50 \%)$. Of $31 \mathrm{GBM}$ positive for PATZ1 staining, 17 displayed,$+ 9++$ and $5+++$ score (Figure 2A-2D, Supplementary Table 1). Among the 12 oligodendrogliomas expressing PATZ1, 4 cases had +, $5++$ and $3+++$ score (Figure $2 \mathrm{E}-2 \mathrm{H}$, Supplementary Table 2). Among the assessed clinicopathological features of GBM (age, gender, site), a high significant correlation and a trend to be correlated with PATZ1 expression was present in the male gender $(p=0.0028)$ and younger patients $(\mathrm{p}=0.0695)$, respectively. Moreover, a statistically significant correlation was observed between PATZ1 immunoreactivity and grading $(\mathrm{p}=0.0286)$ in oligodendrogliomas (Table 1).

By analysing public datasets through the R2: genomic Analysis and Visualization platform (http:// r2.amc.nl), we confirmed in an independent sample cohort of 6 adult non diseased brains, 26 GBMs and 21 oligodendrogliomas [25] that PATZ1 is significantly more expressed in gliomas (including GBMs and oligodendrogliomas) compared to non diseased brain samples (Figure 3A). Moreover, in a data set from the Tumor Cancer Genomic Atlas (TCGA), including 85 samples, sub-classified in classical $(\mathrm{n}=17)$, mesenchymal $(\mathrm{n}=27)$, neural $(\mathrm{n}=17)$ and proneural $(\mathrm{n}=24) \mathrm{GBM}$, we found that PATZ1 expression specifically correlates with the molecular subtype, being highest in proneural and lowest in mesenchymal subtype, with significant differences between each subtype (Figure 3B). Consistently, by studying the gene signature correlated with the expression of PATZ1 in the context of GBM, we found that PATZ1 expression positively associates with proneural genes, including $S O X 2, O L I G 2, D L L 3$,
NOTCH1, PDGFR a and many others, while negatively associates with the mesenchymal marker CD44 and many other genes characterizing the mesenchymal signature (Table 2 and Supplementary Table 3).

Taken together protein and gene expression data, PATZ1 is overexpressed in gliomas compared to normal glia and appears as a specific biomarker of the proneural GBM subtype.

\section{PATZ1 is preferentially expressed in glioma stem cells}

It has been recently reported that a proneurallike gene expression signature is characteristic of GSCs characterized by a full stem phenotype (Gsf lines), growth as floating spheres, CD133 expression and multipotency, while a mesenchymal-like gene expression signature is associated with GSCs characterized by a restricted stem phenotype (Gsr lines), adherent growth, no CD133 expression and limited differentiation $[8$, 26, 27]. Consistently, by analysing the expression profiles of the 9 GSCs and relative sub-clones isolated and characterized by Günter and colleagues (4 with Gsf phenotype and 5 with Gsr phenotype) we found that PATZ1 is significantly enriched in Gsf-GSCs compared with Gsr-GSCs (Figure 3C). The association of PATZ1 expression with CD133 expression was further confirmed by the analysis of two separate experimental datasets consisting of cell lines established from 7 GBMs, 2 oligoastrocytomas and 5 normal foetuses plus primary biopsies from 6 normal brains [28], and 8 fresh primary and non cultured GBMs [29], where PATZ1 expression is highly correlated with that of PROMI (the gene encoding prominin-1/ CD133) (Figure 3D), and is significantly enriched in the CD133+ compared to the CD133- subpopulation (Figure 3E). Consistently, in these cells lines PATZ1 also
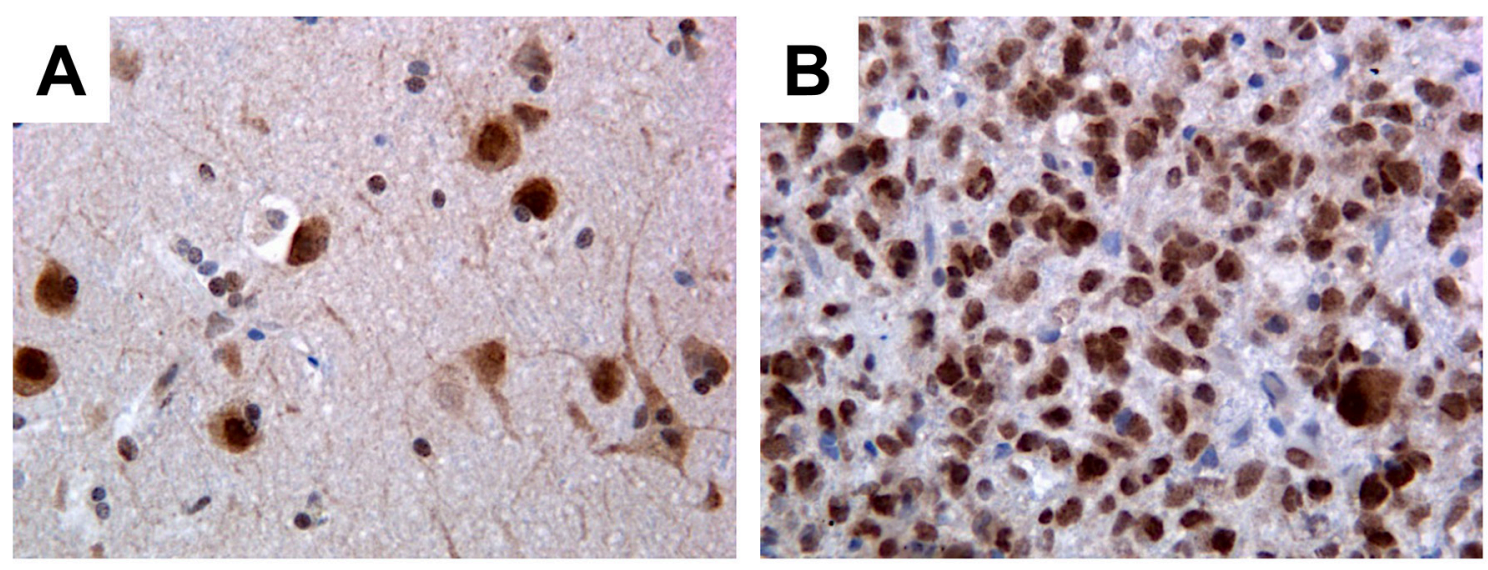

Figure 1: Immunohistochemical detection of PATZ1 in human GBM and perilesional normal cortex. (A) Perilesional normal cortex: only neurons stain positively, mainly in the nucleus, while glial cells are negative. (B) Representative GBM: most of neoplastic cells are positive. Original magnification: 40x. 
Table 1: Fisher's exact test: clinicopathological features and PATZ1 expression

\begin{tabular}{|c|c|c|c|c|}
\hline \multirow{2}{*}{$\begin{array}{l}\text { Variables } \\
\text { GBM }\end{array}$} & \multirow[b]{2}{*}{ n. } & \multicolumn{3}{|c|}{ PATZ1 expression } \\
\hline & & $+/++/+++$ & - & $\mathbf{p}$ \\
\hline Age & 45 & & & \\
\hline$<60$ & 11 & $10(91 \%)$ & $1(9 \%)$ & 0.0695 \\
\hline$\geq 60$ & 34 & $21(62 \%)$ & $13(38 \%)$ & \\
\hline Gender & 45 & & & \\
\hline Males & 30 & $27(90 \%)$ & $3(10 \%)$ & 0.0028 \\
\hline Females & 15 & $7(47 \%)$ & $8(53 \%)$ & \\
\hline Site & 42 & & & \\
\hline Temporal & 22 & $14(64 \%)$ & $8(36 \%)$ & 0.5586 \\
\hline Parietal & 11 & $9(82 \%)$ & $2(18 \%)$ & \\
\hline Frontal & 9 & $6(67 \%)$ & $3(33 \%)$ & \\
\hline \multicolumn{5}{|c|}{ Oligodendrogliomas } \\
\hline Age & 22 & & & \\
\hline$<60$ & 17 & $9(53 \%)$ & $8(47 \%)$ & 0.7805 \\
\hline$\geq 60$ & 5 & $3(60 \%)$ & $2(40 \%)$ & \\
\hline Gender & 22 & & & \\
\hline Males & 15 & $9(60 \%)$ & $6(40 \%)$ & 0.4520 \\
\hline Females & 7 & $3(43 \%)$ & $4(57 \%)$ & \\
\hline Site & 21 & & & \\
\hline Frontal & 14 & $6(43 \%)$ & $8(57 \%)$ & 0.1974 \\
\hline Temporal & 4 & $2(50 \%)$ & $2(50 \%)$ & \\
\hline Occipital & 3 & $3(100 \%)$ & $0(0 \%)$ & \\
\hline Grading & 22 & & & \\
\hline II & 12 & $4(33 \%)$ & $8(67 \%)$ & 0.0286 \\
\hline III & 10 & $8(80 \%)$ & $2(20 \%)$ & \\
\hline
\end{tabular}

correlates with markers of oligodendrocyte precursor cells, including $S O X 8, O L I G 1, O L I G 2$, and $N K X 2.2$, and of the proneural phenotype, such as DLL3,OLIG2 and SOX2 (Supplementary Table 4). All together these results indicate that PATZ1 is preferentially expressed in GSCs in comparison with matched non-GSCs, and is particularly enriched in proneural versus mesenchymal subtype.

To validate the in silico results, we analyzed PATZ1 expression in 6 GSCs (3 growing in adhesion and 3 growing as spheres in laminin-coated dishes) isolated from patients affected by GBM in comparison with matched non-stem tumor cells (Figure 4A). The results confirmed an enriched expression of PATZ1 in stem versus non-stem matched samples ( $\mathrm{P}<0.05$; Figure $4 \mathrm{~B})$. The differences do not reach the statistical significance if we consider each group (sphere forming and growing in adhesion GSCs) singularly, likely because of the low number of samples, but they have a trend to be higher in GSCs compared to matched non-stem tumor cells (data not shown). Moreover, PATZ1 expression was also analyzed in 5 more GBM-derived GSCs, for a total of 11 GSCs, which were sub-divided in two groups on the basis of their growth capacity in laminin-coated dishes (sphere/adherent). As shown in Figure 4C, and consistently with data shown in Figure 3C, PATZ1 expression was highly enriched in GSCs growing as spheres compared to GSCs growing adherent $(\mathrm{P}<0.01)$. All isolated GSCs, independently from their modality to grow in laminin-coated dishes, expressed markers of stemness, as confirmed by immunofluorescence analysis (Figure 4D), at higher levels compared with matched DIFF cells (data not shown). Immunofluorescence analysis confirmed expression of PATZ1 in GSC growing either as spheres or in adhesion and their colocalization 
with the stemness marker Nestin (Figure 4E and data not shown). PATZ1 expression here appears mainly nuclear but a speckled cytosolic expression can be observed as previously described in other cancer cell types [20-22].
We also used the GBM cell lines U87MG to isolate GSC and analyze PATZ1 expression in comparison with matched bulk and differentiated cells (Supplementary Figure 1). PATZ1 protein expression resulted enriched in

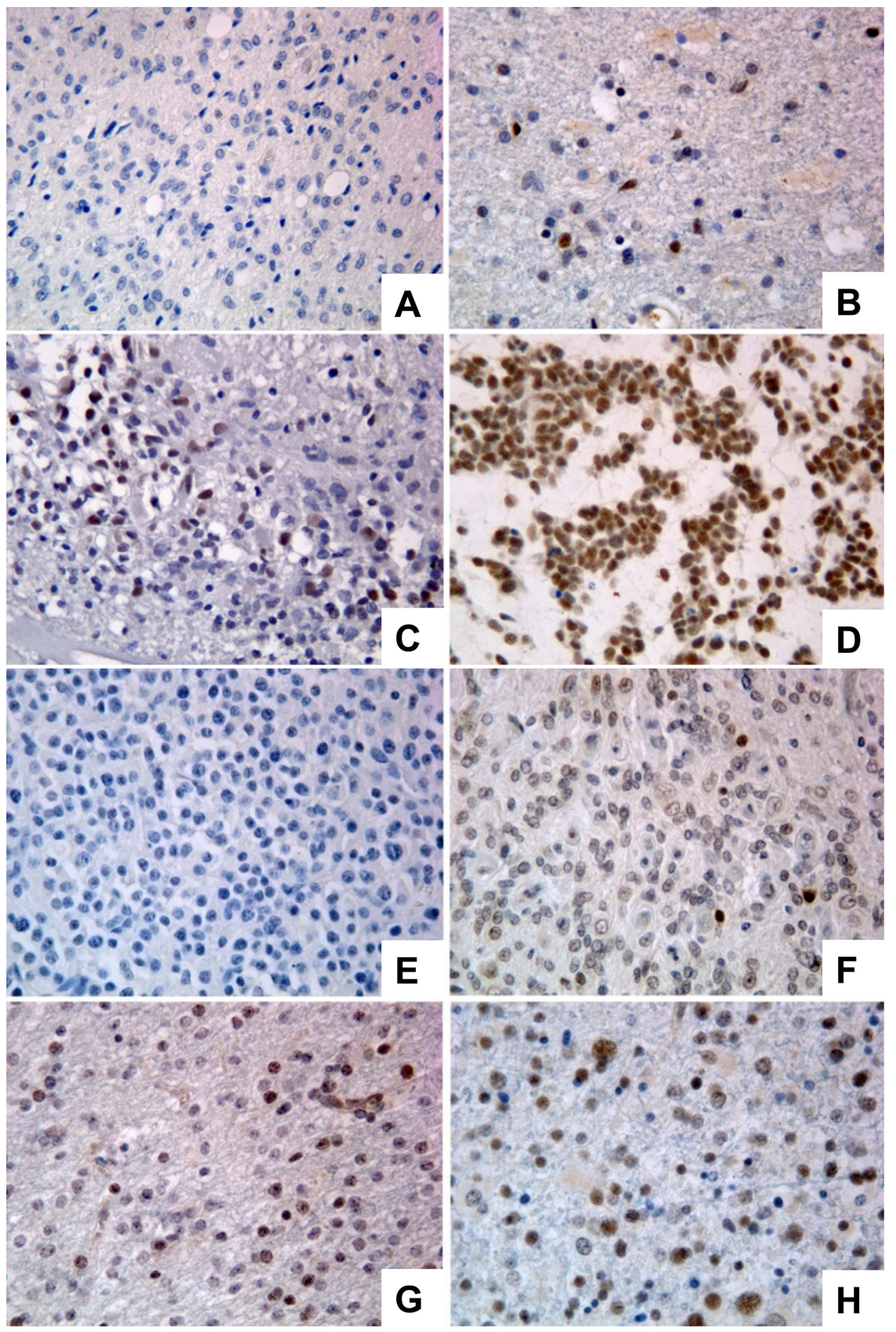

Figure 2: Immunoreactivity score in GBMs and oligodendrogliomas stained for PATZ1. (A) Representative GBM scored 0. (B) Representative GBM scored +. (C) Representative GBM scored ++. (D) Representative GBM scored +++. (E) Representative oligodendroglioma scored 0. (F) Representative oligodendroglioma scored +. (G) Representative oligodendroglioma scored ++. (H) Representative oligodendroglioma scored +++. Original magnification: 40x. 
Table 2: Correlations between $P A T Z 1$ and the proneural and mesenchymal signature in GBM${ }^{\mathrm{a}}$

\begin{tabular}{|c|c|c|c|c|c|}
\hline \multicolumn{3}{|c|}{ Proneural signature } & \multicolumn{3}{|c|}{ Mesenchymal signature } \\
\hline Gene & $\mathbf{r}^{\mathbf{b}}$ & $\mathbf{p}$ & gene & $\mathbf{r}$ & $\mathbf{p}$ \\
\hline CHD7 & 0.649 & $3.9 \mathrm{e}-62$ & $H E X B$ & -0.597 & $3.8 \mathrm{e}-50$ \\
\hline CSNK1E & 0.633 & $3.1 \mathrm{e}-58$ & $S Q R D L$ & -0.583 & $2.7 e-47$ \\
\hline MARCKSL1 & 0.592 & $4.4 \mathrm{e}-49$ & TMBIM1 & -0.537 & $4.1 \mathrm{e}-39$ \\
\hline $\mathrm{SOX} 4$ & 0.580 & 7.1e-47 & IL 15 & -0.535 & 7.1e-39 \\
\hline NOTCH1 & 0.574 & $1.0 \mathrm{e}-45$ & $R A B 32$ & -0.528 & $1.0 \mathrm{e}-37$ \\
\hline$M A P 2$ & 0.564 & $9.4 \mathrm{e}-44$ & $A N X A 4$ & -0.524 & $5.1 \mathrm{e}-37$ \\
\hline SOX11 & 0.557 & $1.1 \mathrm{e}-42$ & $S 100 A 4$ & -0.523 & $5.7 e-37$ \\
\hline$D L L 3$ & 0.549 & $3.8 \mathrm{e}-41$ & $F C G R 2 B$ & -0.522 & $1.0 \mathrm{e}-36$ \\
\hline PODXL2 & 0.545 & $1.3 \mathrm{e}-40$ & $R R A S$ & -0.518 & $4.4 \mathrm{e}-36$ \\
\hline MMP16 & 0.539 & $1.4 \mathrm{e}-39$ & P4HA2 & -0.513 & $2.2 \mathrm{e}-35$ \\
\hline FXYD6 & 0.535 & $6.9 \mathrm{e}-39$ & VAMP5 & -0.505 & $3.8 \mathrm{e}-34$ \\
\hline TOP2B & 0.532 & $1.8 \mathrm{e}-38$ & $N P C 2$ & -0.499 & $2.7 e-33$ \\
\hline PHF16 & 0.532 & $2.2 \mathrm{e}-38$ & $C A S T$ & -0.497 & $6.3 e-33$ \\
\hline SEZ6L & 0.526 & $2.1 \mathrm{e}-37$ & $P L S 3$ & -0.497 & $4.7 e-33$ \\
\hline$B C A N$ & 0.524 & $4.0 \mathrm{e}-37$ & COPZ2 & -0.495 & $1.1 \mathrm{e}-32$ \\
\hline CRMP1 & 0.519 & $3.1 \mathrm{e}-36$ & PLAUR & -0.495 & $9.4 \mathrm{e}-33$ \\
\hline$N L G N 3$ & 0.518 & $4.2 \mathrm{e}-36$ & $C L E C 2 B$ & -0.490 & $5.4 \mathrm{e}-32$ \\
\hline WDR6 & 0.511 & $3.9 \mathrm{e}-35$ & $L G A L S 3$ & -0.477 & $3.9 e-30$ \\
\hline PHLPPI & 0.500 & $1.8 \mathrm{e}-33$ & $L Y 96$ & -0.476 & $5.6 e-30$ \\
\hline MTSS1 & 0.494 & $1.5 \mathrm{e}-32$ & CLIC1 & -0.475 & $6.1 \mathrm{e}-30$ \\
\hline OLIG2 & 0.494 & $1.6 \mathrm{e}-32$ & $P I G P$ & -0.473 & $1.1 \mathrm{e}-29$ \\
\hline$N R X N 2$ & 0.488 & $1.2 \mathrm{e}-31$ & $A L O X 5$ & -0.466 & $1.0 \mathrm{e}-28$ \\
\hline PAFAH1B3 & 0.488 & $1.2 \mathrm{e}-31$ & TNFAIP8 & -0.465 & $1.3 \mathrm{e}-28$ \\
\hline$D B N 1$ & 0.484 & $4.1 \mathrm{e}-31$ & CSTA & -0.461 & $4.3 e-28$ \\
\hline MMP15 & 0.483 & $5.8 \mathrm{e}-31$ & S100A11 & -0.461 & $5.0 \mathrm{e}-28$ \\
\hline FLRT1 & 0.479 & $1.8 \mathrm{e}-30$ & CTSB & -0.453 & $4.9 \mathrm{e}-27$ \\
\hline$D P F 1$ & 0.479 & $1.9 \mathrm{e}-30$ & CASP4 & -0.453 & $4.5 e-27$ \\
\hline ASCL1 & 0.479 & $1.7 \mathrm{e}-30$ & $A N X A 2$ & -0.447 & $2.9 \mathrm{e}-26$ \\
\hline$C R B 1$ & 0.476 & $5.3 \mathrm{e}-30$ & $R A B 27 A$ & -0.442 & $1.1 \mathrm{e}-25$ \\
\hline$D C X$ & 0.472 & $1.5 \mathrm{e}-29$ & $M G S T 2$ & -0.440 & $1.9 \mathrm{e}-25$ \\
\hline SATB1 & 0.472 & $1.6 \mathrm{e}-29$ & SP100 & -0.439 & $2.7 \mathrm{e}-25$ \\
\hline ZNF510 & 0.471 & $2.1 \mathrm{e}-29$ & $A R P C 1 B$ & -0.437 & $4.6 e-25$ \\
\hline RUFY3 & 0.467 & $7.5 e-29$ & $T L R 2$ & -0.437 & $4.4 \mathrm{e}-25$ \\
\hline GNG4 & 0.467 & $7.8 \mathrm{e}-29$ & $A S L$ & -0.433 & $1.6 e-24$ \\
\hline MYT1 & 0.461 & $5.1 \mathrm{e}-28$ & $K Y N U$ & -0.433 & $1.3 \mathrm{e}-24$ \\
\hline
\end{tabular}

(Continued) 


\begin{tabular}{|c|c|c|c|c|c|}
\hline \multicolumn{3}{|c|}{ Proneural signature } & \multicolumn{3}{|c|}{ Mesenchymal signature } \\
\hline Gene & $\mathbf{r}^{\mathbf{b}}$ & $\mathbf{p}$ & gene & $\mathbf{r}$ & $\mathbf{p}$ \\
\hline CASK & 0.451 & $9.9 \mathrm{e}-27$ & PROCR & -0.433 & $1.7 \mathrm{e}-24$ \\
\hline$C D K 5 R 1$ & 0.446 & $4.4 \mathrm{e}-26$ & FHL2 & -0.433 & $1.4 \mathrm{e}-24$ \\
\hline$V A X 2$ & 0.442 & $1.1 \mathrm{e}-25$ & $L G A L S 1$ & -0.432 & $2.1 \mathrm{e}-24$ \\
\hline GSK3B & 0.436 & $5.9 \mathrm{e}-25$ & TIMP1 & -0.432 & $1.8 \mathrm{e}-24$ \\
\hline NCAM1 & 0.430 & $3.7 \mathrm{e}-24$ & PHF11 & -0.432 & $2.1 \mathrm{e}-24$ \\
\hline$M A P T$ & 0.429 & $4.5 \mathrm{e}-24$ & MAN1A1 & -0.425 & $1.3 e-23$ \\
\hline$C K B$ & 0.425 & $1.4 \mathrm{e}-23$ & AMPD3 & -0.424 & $1.5 \mathrm{e}-23$ \\
\hline$C B X 1$ & 0.425 & $1.3 \mathrm{e}-23$ & POLD4 & -0.418 & $7.2 \mathrm{e}-23$ \\
\hline$K I F 21 B$ & 0.425 & $1.3 \mathrm{e}-23$ & CYBRD1 & -0.418 & $7.1 \mathrm{e}-23$ \\
\hline MYO10 & 0.424 & $1.6 \mathrm{e}-23$ & CHI3L1 & -0.418 & $7.9 \mathrm{e}-23$ \\
\hline NOL4 & 0.423 & $2.4 \mathrm{e}-23$ & IFI30 & -0.416 & $1.2 \mathrm{e}-22$ \\
\hline MPPED2 & 0.422 & $2.8 \mathrm{e}-23$ & $F C G R 2 A$ & -0.414 & $2.1 \mathrm{e}-22$ \\
\hline$B C O R$ & 0.420 & $5.4 \mathrm{e}-23$ & ACSL1 & -0.413 & $3.0 \mathrm{e}-22$ \\
\hline CSPG5 & 0.419 & $6.0 \mathrm{e}-23$ & $M A N 2 A 1$ & -0.413 & $2.7 e-22$ \\
\hline CLASP 2 & 0.414 & $2.3 e-22$ & SYPL1 & -0.412 & $3.7 e-22$ \\
\hline$H M G B 3$ & 0.406 & $1.5 \mathrm{e}-21$ & $I Q G A P I$ & -0.405 & $2.4 \mathrm{e}-21$ \\
\hline TMCC1 & 0.403 & $3.3 e-21$ & $R A C 2$ & -0.403 & $3.6 \mathrm{e}-21$ \\
\hline$N K X 2-2$ & 0.400 & $7.1 \mathrm{e}-21$ & ICAM3 & -0.402 & $4.3 e-21$ \\
\hline RALGPS1 & 0.400 & $7.1 \mathrm{e}-21$ & $M S 4 A 4 A$ & -0.401 & $6.6 e-21$ \\
\hline $\mathrm{SOX} 2$ & 0.399 & $9.7 \mathrm{e}-21$ & CRYZ & -0.401 & $6.2 \mathrm{e}-21$ \\
\hline GRIA2 & 0.399 & $1.0 \mathrm{e}-20$ & ANXA1 & -0.400 & $8.2 \mathrm{e}-21$ \\
\hline ТТYН1 & 0.397 & $1.4 \mathrm{e}-20$ & PTGER4 & -0.396 & $2.1 \mathrm{e}-20$ \\
\hline ZNF184 & 0.397 & $1.5 \mathrm{e}-20$ & $L T B P 2$ & -0.396 & $2.2 \mathrm{e}-20$ \\
\hline$S C N 3 A$ & 0.396 & $1.9 \mathrm{e}-20$ & SLC16A3 & -0.395 & $2.4 \mathrm{e}-20$ \\
\hline$K L R C 3$ & 0.394 & $3.2 \mathrm{e}-20$ & $N C F 2$ & -0.393 & $3.8 \mathrm{e}-20$ \\
\hline AMOTL2 & 0.391 & $6.6 \mathrm{e}-20$ & $T G F B I$ & -0.391 & $6.2 \mathrm{e}-20$ \\
\hline TAF5 & 0.389 & $1.0 \mathrm{e}-19$ & $M A F B$ & -0.390 & $7.6 e-20$ \\
\hline DUSP26 & 0.383 & $3.8 \mathrm{e}-19$ & RHOG & -0.388 & $1.4 \mathrm{e}-19$ \\
\hline$R A P 2 A$ & 0.383 & $4.4 \mathrm{e}-19$ & CTSC & -0.387 & $1.5 \mathrm{e}-19$ \\
\hline$C D C 7$ & 0.380 & 8.1e-19 & SWAP70 & -0.386 & $2.2 \mathrm{e}-19$ \\
\hline SRGAP3 & 0.377 & $1.7 \mathrm{e}-18$ & IGFBP6 & -0.383 & $4.1 \mathrm{e}-19$ \\
\hline WASF1 & 0.375 & $2.4 \mathrm{e}-18$ & SERPINA1 & -0.382 & $5.3 e-19$ \\
\hline$I C K$ & 0.372 & $5.2 \mathrm{e}-18$ & MFSD1 & -0.382 & $5.6 e-19$ \\
\hline$R A D 21$ & 0.371 & $6.4 \mathrm{e}-18$ & $A C P P$ & -0.381 & $6.1 \mathrm{e}-19$ \\
\hline GSTA4 & 0.368 & $1.1 \mathrm{e}-17$ & TNFAIP3 & -0.380 & $8.9 \mathrm{e}-19$ \\
\hline SEC61A2 & 0.367 & $1.5 \mathrm{e}-17$ & ILIRI & -0.380 & $8.3 e-19$ \\
\hline
\end{tabular}

(Continued) 


\begin{tabular}{|c|c|c|c|c|c|}
\hline \multicolumn{3}{|c|}{ Proneural signature } & \multicolumn{3}{|c|}{ Mesenchymal signature } \\
\hline Gene & $\mathbf{r}^{\mathbf{b}}$ & $\mathbf{p}$ & gene & $\mathbf{r}$ & $\mathbf{p}$ \\
\hline$E P H B 1$ & 0.364 & $2.8 \mathrm{e}-17$ & SYNGR2 & -0.377 & $1.6 \mathrm{e}-18$ \\
\hline DPYSL4 & 0.363 & $3.3 e-17$ & CASP8 & -0.376 & $1.9 \mathrm{e}-18$ \\
\hline$N R X N 1$ & 0.360 & $6.5 e-17$ & C5AR1 & -0.375 & $2.4 \mathrm{e}-18$ \\
\hline PDGRA & 0.352 & $3.6 \mathrm{e}-16$ & CTSZ & -0.375 & $2.6 \mathrm{e}-18$ \\
\hline$E R B B 3$ & 0.352 & $3.8 \mathrm{e}-16$ & ARHGAP29 & -0.369 & $9.6 \mathrm{e}-18$ \\
\hline$A B A T$ & 0.350 & $5.3 \mathrm{e}-16$ & $\mathrm{SHCl}$ & -0.366 & $1.8 \mathrm{e}-17$ \\
\hline$G A D D 45 G$ & 0.345 & $1.4 \mathrm{e}-15$ & SERPINE1 & -0.366 & $1.7 \mathrm{e}-17$ \\
\hline$C D C 25 A$ & 0.341 & $3.7 \mathrm{e}-15$ & MSR1 & -0.366 & $1.9 \mathrm{e}-17$ \\
\hline$A T P 1 A 3$ & 0.338 & $5.8 \mathrm{e}-15$ & FXYD5 & -0.365 & $2.2 \mathrm{e}-17$ \\
\hline YPEL1 & 0.336 & $9.6 e-15$ & THBD & -0.364 & $2.8 \mathrm{e}-17$ \\
\hline FBXO21 & 0.335 & $1.1 \mathrm{e}-14$ & LAIRI & -0.363 & $3.6 \mathrm{e}-17$ \\
\hline ARHGEF9 & 0.335 & $1.1 \mathrm{e}-14$ & $C D 14$ & -0.359 & $8.9 \mathrm{e}-17$ \\
\hline$H D A C 2$ & 0.331 & $2.2 \mathrm{e}-14$ & $G R N$ & -0.358 & $1.1 \mathrm{e}-16$ \\
\hline ZNF248 & 0.328 & $4.3 \mathrm{e}-14$ & PTPRC & -0.354 & $2.6 \mathrm{e}-16$ \\
\hline FHOD3 & 0.324 & $8.5 \mathrm{e}-14$ & $L Y 75$ & -0.353 & $3.1 \mathrm{e}-16$ \\
\hline HOXD3 & 0.320 & $1.9 \mathrm{e}-13$ & GNA15 & -0.350 & $5.6 \mathrm{e}-16$ \\
\hline TSAPN3 & 0.318 & $2.8 \mathrm{e}-13$ & $V D R$ & -0.349 & 7.1e-16 \\
\hline ТOРВP1 & 0.318 & $3.0 \mathrm{e}-13$ & CASP1 & -0.349 & $6.3 \mathrm{e}-16$ \\
\hline EPB41L5 & 0.317 & $3.1 \mathrm{e}-13$ & $I T G B 2$ & -0.346 & $1.4 \mathrm{e}-15$ \\
\hline$B E X 1$ & 0.316 & $3.9 \mathrm{e}-13$ & PTPN22 & -0.345 & $1.7 \mathrm{e}-15$ \\
\hline$D G K I$ & 0.314 & $5.7 \mathrm{e}-13$ & EMP3 & -0.345 & $1.7 \mathrm{e}-15$ \\
\hline STMN1 & 0.314 & $6.1 \mathrm{e}-13$ & $T C I R G 1$ & -0.344 & $1.8 \mathrm{e}-15$ \\
\hline CA10 & 0.308 & $1.7 \mathrm{e}-12$ & $S L A M F 8$ & -0.344 & $2.0 \mathrm{e}-15$ \\
\hline MCM10 & 0.307 & $1.9 \mathrm{e}-12$ & SIGLEC7 & -0.344 & $1.7 \mathrm{e}-15$ \\
\hline$P 2 R X 7$ & 0.305 & $3.0 \mathrm{e}-12$ & ITGAM & -0.338 & $5.7 \mathrm{e}-15$ \\
\hline PDE 10A & 0.295 & $1.6 \mathrm{e}-11$ & SCPEPI & -0.336 & $8.8 \mathrm{e}-15$ \\
\hline$F G F 9$ & 0.293 & $2.2 \mathrm{e}-11$ & TGFBR2 & -0.333 & $1.5 \mathrm{e}-14$ \\
\hline$R A B 33 A$ & 0.293 & $2.1 \mathrm{e}-11$ & STAT6 & -0.333 & $1.6 \mathrm{e}-14$ \\
\hline TMEM35 & 0.290 & $3.6 \mathrm{e}-11$ & LILRB2 & -0.332 & $2.1 \mathrm{e}-14$ \\
\hline GRID2 & 0.290 & $3.6 \mathrm{e}-11$ & SIGLEC9 & -0.330 & $3.0 \mathrm{e}-14$ \\
\hline$P P M 1 D$ & 0.288 & $4.8 \mathrm{e}-11$ & $P L A U$ & -0.324 & $8.6 \mathrm{e}-14$ \\
\hline PAK7 & 0.286 & $6.6 \mathrm{e}-11$ & ARSJ & -0.324 & $9.5 \mathrm{e}-14$ \\
\hline$N A N O G$ & 0.284 & $1.0 \mathrm{e}-10$ & $S E C 24 D$ & -0.323 & $1.1 \mathrm{e}-13$ \\
\hline PPMIE & 0.280 & $1.8 \mathrm{e}-10$ & TRIM38 & -0.319 & $2.3 \mathrm{e}-13$ \\
\hline MAST1 & 0.279 & $2.2 \mathrm{e}-10$ & ELF4 & -0.318 & $2.7 \mathrm{e}-13$ \\
\hline
\end{tabular}

a All the genes belong to either the proneural or mesenchymal signatures as described by Verhaak et al. [7].

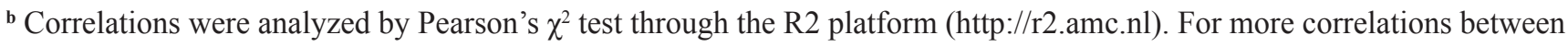
PATZ1 and the mesenchymal signature see Supplementary Table 5. 
A

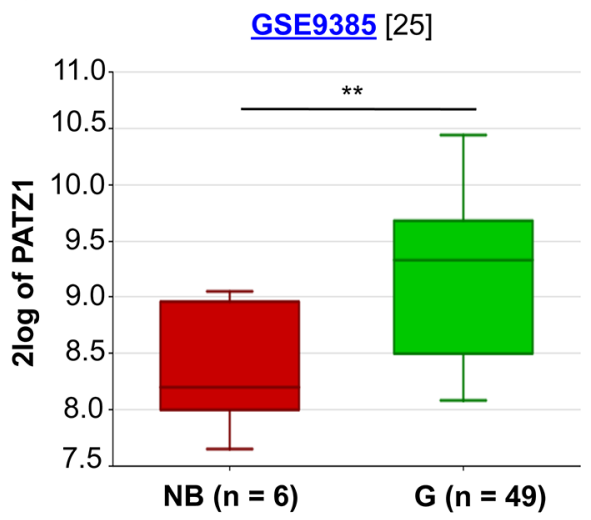

B

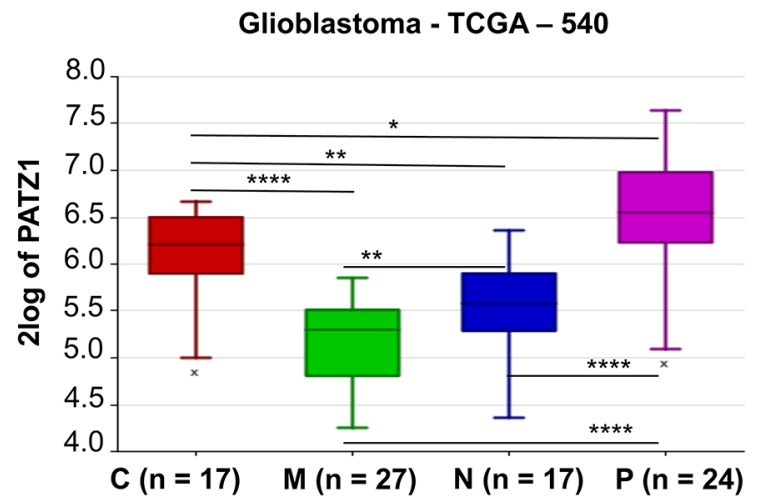

C GSE8049 [26]
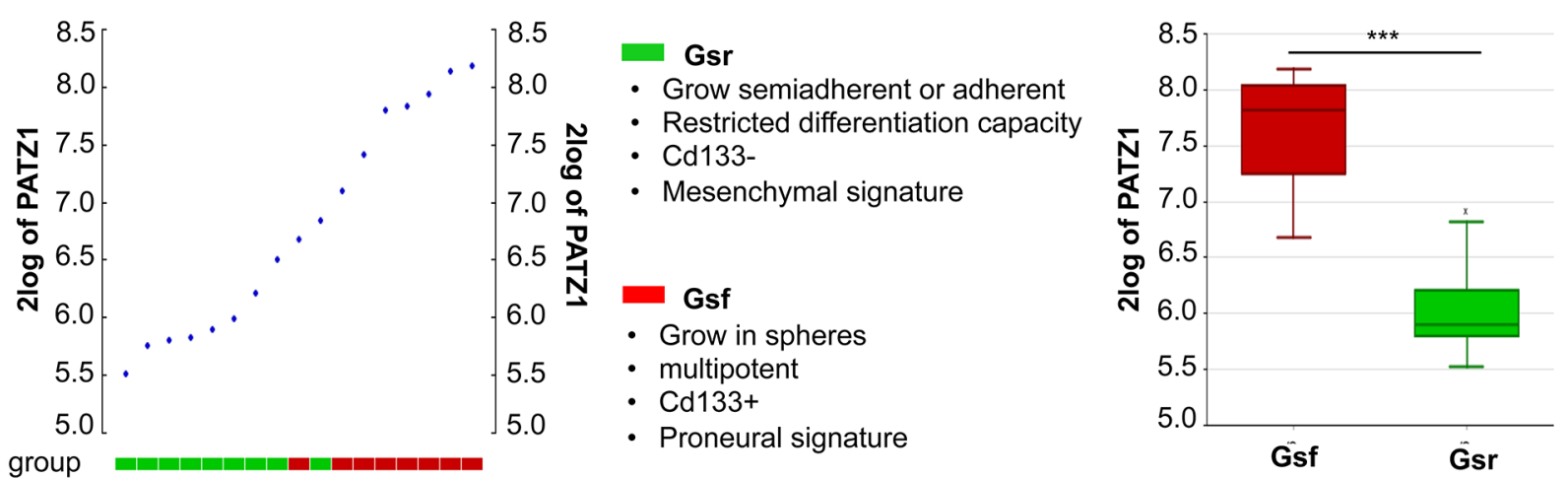

D

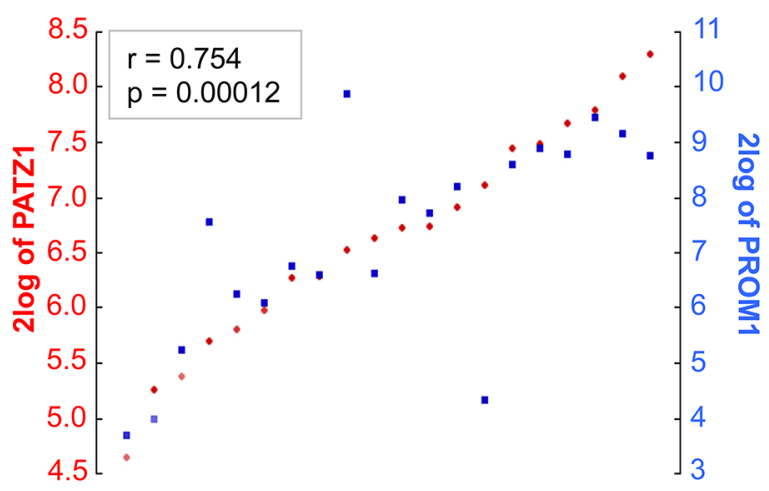

$\mathbf{E}$

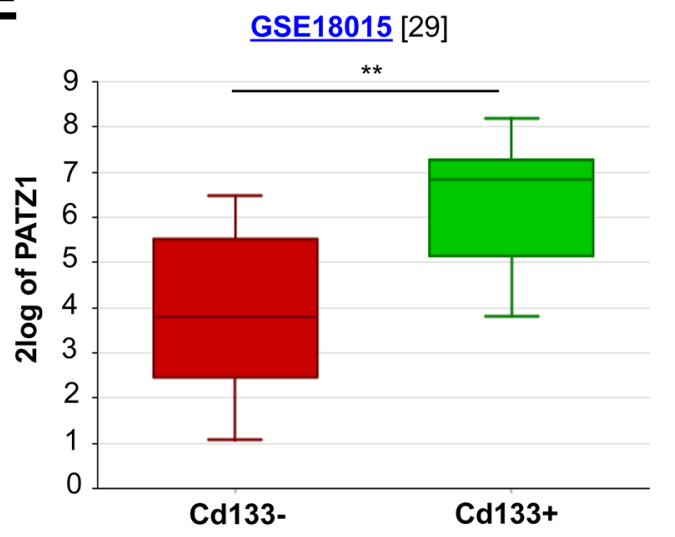

Figure 3: In silico meta-analysis of PATZ1 expression in human GBM tissues and cell lines. (A) Box-plot comparing PATZ1 expression in normal brain (NB) and gliomas of different grade (G). The data were analyzed by one-way analysis of variance (ANOVA) through the R2 web platform. (B) Box-plot showing PATZ1 expression in the different GBM subtypes and statistical analysis of the differences among them. $\mathrm{C}=$ classical, $\mathrm{M}=$ mesenchymal, $\mathrm{N}=$ neural, $\mathrm{P}=$ proneural. The data were analyzed by one-way analysis of variance (ANOVA) through the R2 web platform. (C) On the left, YY-plot in GSCs (ordered by PATZ1 expression). The cells are divided in two group as indicated in the figure. On the right, box-plot comparing PATZ1 expression in the two groups. (D) YY-plot correlating PATZ1 and PROM1 expression in stem cells derived from GBM $(\mathrm{n}=7)$, oligoastrocytoma $(\mathrm{n}=2)$, normal human foetus $(\mathrm{n}=5)$ and primary biopsies of non-malignant brain tissue $(n=6)$. Significance of correlation (inbox) was analyzed by Pearson's $\chi^{2}$ test through the R2 web platform (http://r2.amc.nl). (E) Box-plot comparing PATZ1 expression in primary GBM sorted for Cd133 expression (negative/positive). The data were analyzed by one-way analysis of variance (ANOVA) through the R2 web platform. * ${ }^{*}<0.05 ; * *, p<0.01 ; * * *, p<0.001$; $* * * *, p<0.0001$. Datasets for each cohort of samples are indicated in the figure with the relative reference in brackets. $2 \log$ of PATZ1 $=$ logarithmic values of PATZ1 expression with base of 2 . 
GSC versus both bulk and differentiated matched cells and correlated with expression of platelet-derived growth factor receptor $\beta$ (PDGFR $\beta)$, a stem cell-specific marker in human GBM [30].

To further confirm in vivo the association of PATZ1 with the stem cell compartment of the GBM, we performed immunofluorescence labeling with antibodies anti-PATZ1 and GSC markers, including NESTIN and OCT-4, in 5 GBMs positive for PATZ1 expression. As shown in Figure 5, PATZ1 (red nuclear signal) was co- expressed with NESTIN (green cytoplasmic signal) in a sub-population of neoplastic cells. In these cells co-localization of OCT-4 (green nuclear signal) with PATZ1 was also evident.

\section{PATZ1 expression levels predict survival of GBM patients}

The proneural GBM subtype is characterized by a trend toward longer survival, but is totally unresponsive
A
DIFF
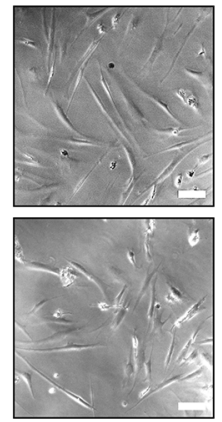

B

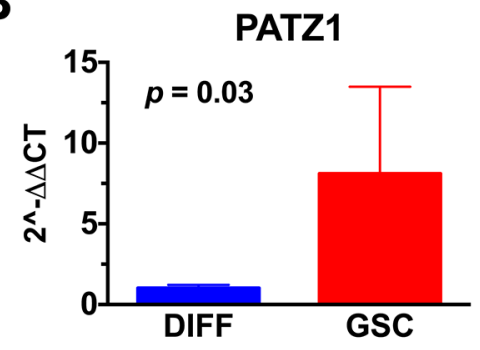

C
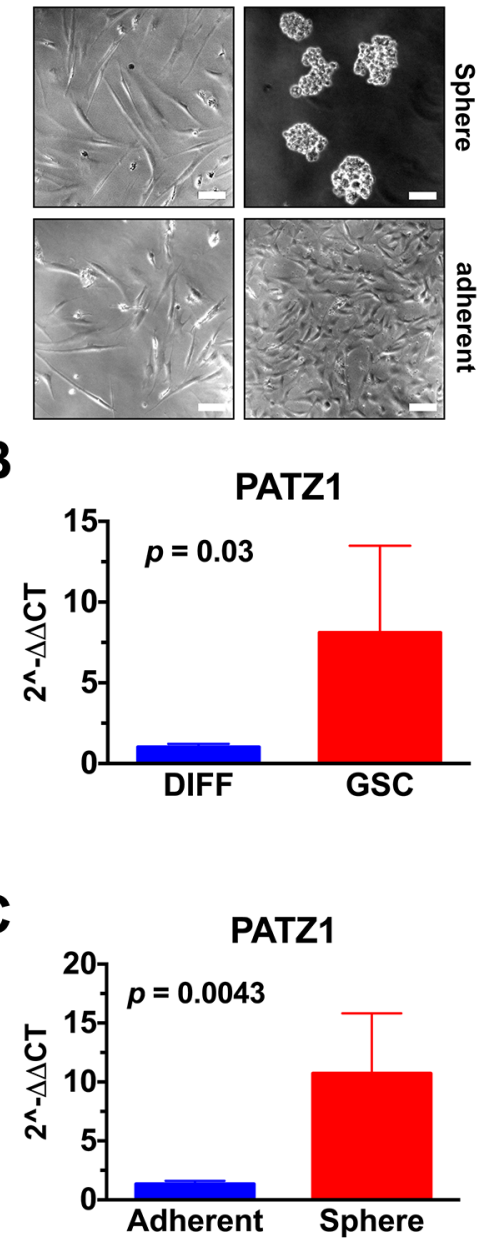

PATZ1
D

E
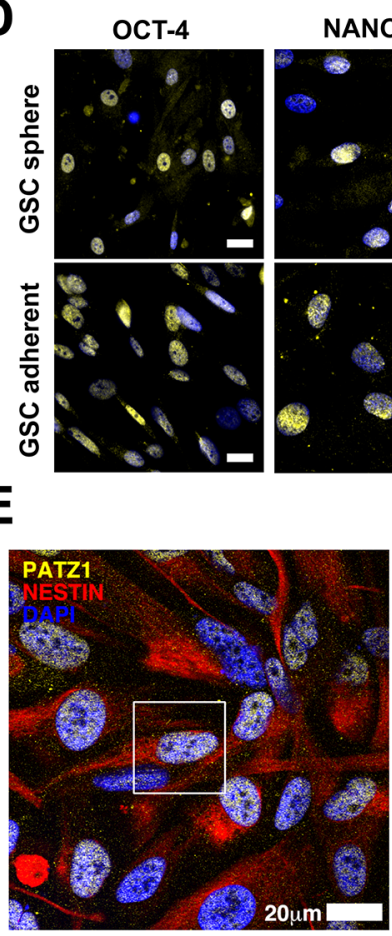

NANOG
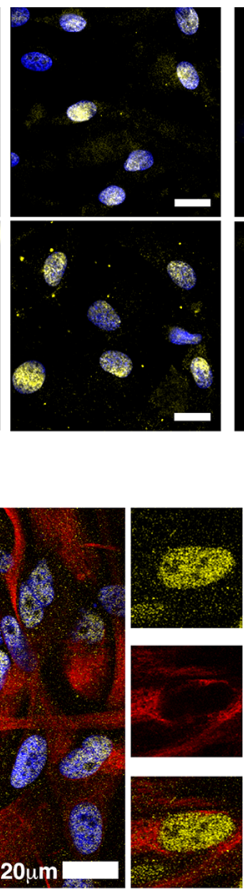
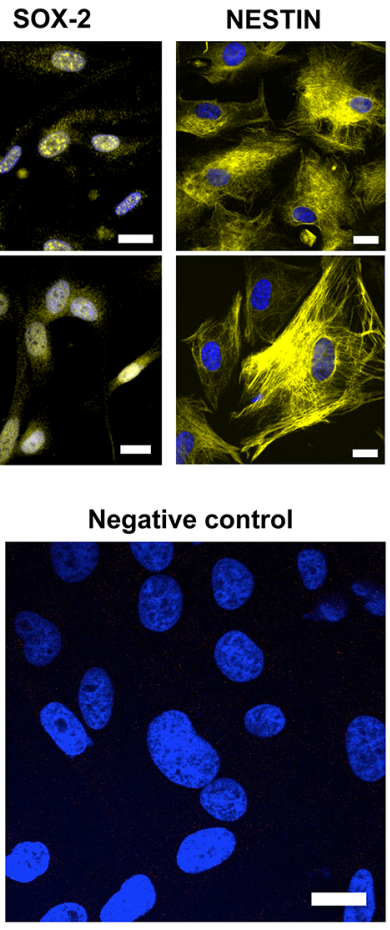
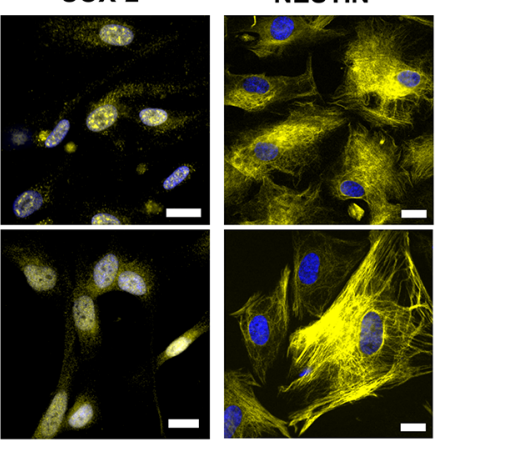

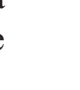


to aggressive treatment with concurrent chemo- and radiotherapy [7]. Consistent with the enrichment of PATZ1 in the proneural subtype, we showed in our local cohort of gliomas, that patients with low PATZ1 score $(0 /+)$ had a worse overall survival (OS) than patients with high PATZ1 score $(++/+++)(\mathrm{HR}=2.525,95 \% \mathrm{CI}=1.208$ $5.280, \mathrm{p}=0.0138$ ) (Figure 6A). The median OS for 16 patients with high PATZ1 was 36 months, in contrast to 12 months for 28 patients with low or absent PATZ1. Similarly, when we extended survival analyses to a larger cohort of GBM samples $(n=85)$, in which all subtypes were similarly represented (GBM - TCGA - 540), both OS and progression-free survival (PFS) were significantly correlated to PATZ1 expression, being worse in patients expressing low levels of PATZ1 (Supplementary Figure 2 ). In this same cohort of samples proneural GBMs have longer survival compared with mesenchymal subtype (Supplementary Figure 2, Panel C). Interestingly, also when we restricted the analysis to the proneural subset of GBM, Kaplan-Meier survival curves, followed by logrank test, showed that PATZ1 expression stratifies these patients $(n=24)$ in two statistically different subgroups where low PATZ1 has worse OS $(\mathrm{HR}=3.191,95 \% \mathrm{CI}=$ 2.355-14.31, $\mathrm{p}=0.001)$ and PFS (HR $=3.595,95 \% \mathrm{CI}$ $=2.785-19.06, \mathrm{p}=0.0006)$ (Figure 6B-6C). The median OS for 10 patients with high PATZ1 expression was 53 months, in contrast to 10 months for 14 patients with low PATZ1. Even more strikingly, the median PFS for patients with high PATZ1 was 63 months versus 6 months for patients with low PATZ1. Moreover, the 5-year PFS was about $40 \%$ for proneural GBM patients with high PATZ1 versus 0 with low PATZ1. In the same group of patients, using a multivariate Cox regression analysis, including known prognostic factors, such as age at diagnosis and methylation of the MGMT gene, low expression of PATZ1 resulted an independent prognostic factor for OS survival $(\mathrm{HR}=0.2886,95 \% \mathrm{CI}=0.0982-0.8482, \mathrm{p}=0.0246)$ and PFS $(\mathrm{HR}=0.2458,95 \% \mathrm{CI}=0.0802-0.7534, \mathrm{p}=0.0146)$.

These data suggest that PATZ1 expression has a crucial impact on outcome of GBM patients with a proneural classification, and could be used as an independent prognostic marker to predict survival and response to treatment.

\section{PATZ1 downregulates CXCR4 expression in GBM}

Remarkably, low PATZ1 samples shown in Figure $6 \mathrm{~B}$ and $6 \mathrm{C}$ were mostly characterized (11 out of 14 ) by increased expression of the G-protein coupled receptor CXCR4 (Supplementary Table 5), which has been shown to induce and assist in the maintenance of a mesenchymal expression profile in GBM cells [31] and is overexpressed in CD133+ cells from human GBMs resistant to chemotherapy [32]. Indeed, we found that CXCR4 was a high significant prognostic and predictive factor in proneural GBM, were high CXCR4 patients show worse

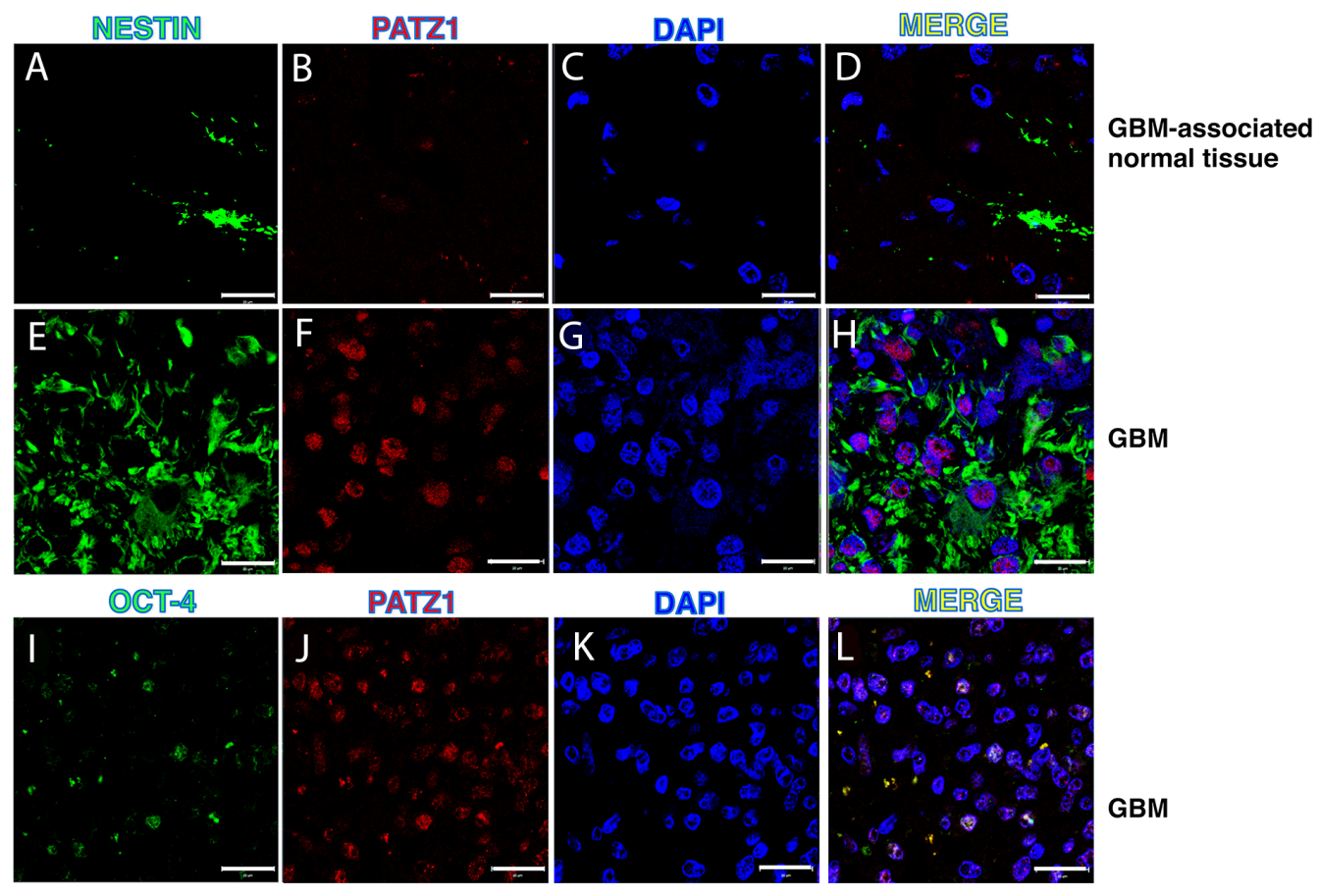

Figure 5: PATZ1 localization in the stem cell compartment of GBM. Representative confocal microscopy images of GBM (two samples with high PATZ1 score (+++) and GBM-associated normal tissues stained with anti-NESTIN (A, E), anti-OCT-4 (I) and antiPATZ1 (B, F, J). (D, H, L) Merge images showing co-localization of PATZ1 with either NESTIN or OCT-4. Scale bar: $20 \mu \mathrm{m}$. (C, G, K) Nuclei are depicted by the blue fluorescence of DAPI. 
outcome considering both OS and PFS survival curves (Figure 7A-7B), and negatively correlated with PATZ1 in these patients $(r=-0.449 ; p=0.03)$ (Figure 7C). A similar negative correlation between PATZ1 and CXCR4 was also observed in GSCs (Supplementary Figure 3).

In order to investigate a possible role of PATZ1 in downregulating CXCR4 gene expression in GBM cells, we transiently transfected the VS-GB cells, a GBMderived primary cell line that does not express PATZ1, with a plasmid expressing PATZ1, and measured CXCR4 mRNA and protein levels by qRT-PCR and western blot, respectively (Figure 7D). A significant decrease of both mRNA and protein levels was observed in cells expressing PATZ1 compared to empty vector-transfected control, supporting an inhibitory role of PATZ1 on CXCR4 expression. This is consistent with data extracted from the Trafac homology server, showing that the CXCR4 promoter harbor consensus sequence for PATZ1 [33], and with data extracted from our previous analysis of Patz1-knockout mouse embryonic fibroblasts [34], showing that Patz1null mouse embryonic fibroblasts express a 4-fold change increase of Cxcr4 compared to wild-type littermate controls.

\section{DISCUSSION}

One of the most important hallmarks of GBM is the marked heterogeneity within and across these tumors, which has been attributed to cancer cell plasticity [35]. According to the cancer stem-cell model some cancers are organized into a hierarchy of subpopulations of tumorigenic cancer stem cells, which drive tumor growth, therapy resistance and disease progression. It is therefore imperative to clarify the markers that can be used to identify these cells and the context in which they work [36]. It has been recently proposed that patient-derived glioblastoma stem-like cells (GSCs) can be sub-divided in two main groups, one characterized by a proneural-like phenotype and the other showing a mesenchymal-like phenotype according to the molecular subtype classification of the TCGA [7-8]. Phenotypically, proneural GSCs exhibit non-adherent sphere forming growth in vitro and circumscribed, non-invasive growth in vivo. In contrast, mesenchymal cells grow semiadherently in vitro and show invasive growth in vivo [8, 37]. Accordingly, patients with proneural GBM have a

\section{A}

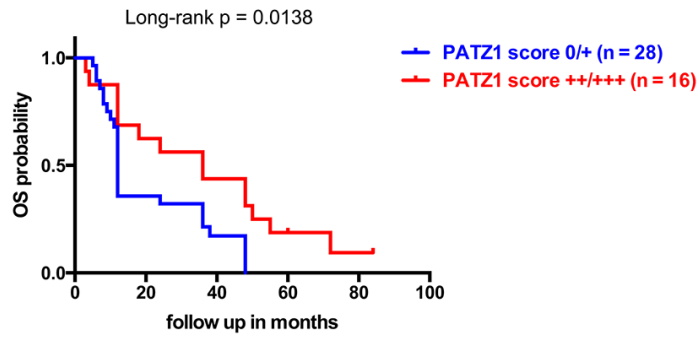

B

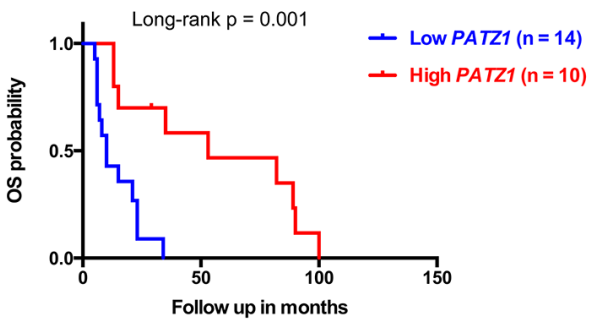

C

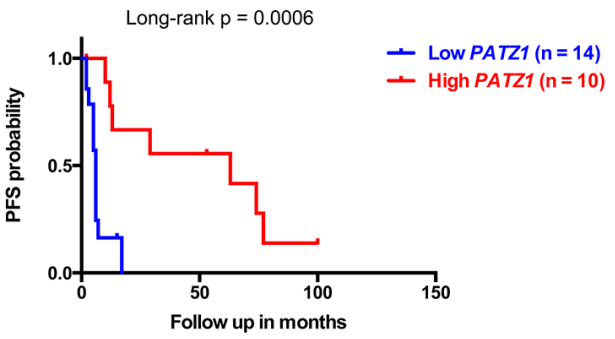

Figure 6: PATZ1 expression negatively correlates with worse survival in GBM patients. (A) Overall (OS) Kaplan-Meier survival curves of GBM patients shown in Supplementary Table 1 stratified by protein levels of PATZ1, as indicated. (B) OS and (C) progression-free (PFS) Kaplan-Meier curves of the proneural subset of GBM patients from the TCGA data set shown in Figure 4B. Note that patients with lower PATZ1 expression have a worse survival rate than patients with higher PATZ1 as assessed by log-rank test. 
trend toward longer survival [7], whereas patients with mesenchymal GBM show the worst outcome [38].

In this study we analyzed expression of the Kruppel-type Zinc Finger transcription factor PATZ1 in GBM and oligodedrogliomas, finding it was highly expressed in a significant number of cases, whereas it was undetectable in normal glia. Moreover, we showed that PATZ1 is expressed in GSCs both in vitro (in GBMderived stem cells) and in vivo (human tissue specimens), is downregulated in differentiated cells from the same tumor as compared to GSCs, and its expression is higher in GSCs growing as spheres (likely proneural) than in GSCs growing as adherent cells (likely mesenchymal). These observations were validated and completed in independent glioma datasets, finding a significant overlap of high PATZ1 expression with the proneural subtype and conversely of low PATZ1 expression with the mesenchymal subtype in both GBMs and GSCs. Since PATZ1 has been described as an inhibitor of cell proliferation in some cancer cell contexts [13,20,39], we would expect that GSCs growing as spheres that express higher levels of PATZ1 compared to GSCs growing in adhesion may proliferate less. However, since there are no differences in the proliferation rate between GSCs growing as spheres and those growing as adherent cells [26], we concluded that PATZ1 is not associated with proliferation in these cells. Interestingly, confocal microscopy analysis of human GBM specimens showed that PATZ1 was expressed in the NESTIN+ subpopulation, which has been recently shown to be crucial for tumor recurrence after treatment with the chemotherapeutic agent temozolomide [10].

Finally, we characterized the prognostic impact of PATZ1 expression first in our local cases of GBM,
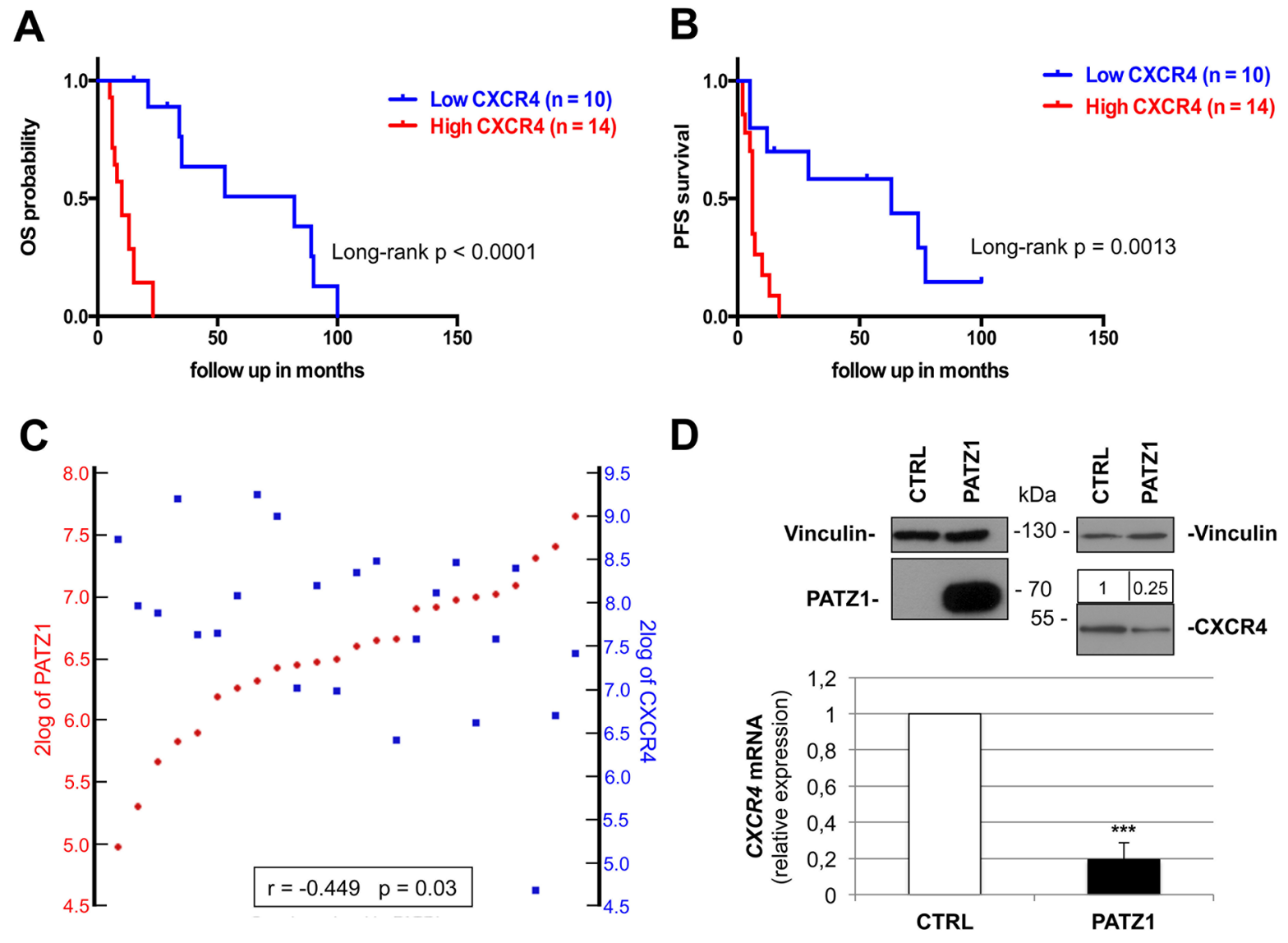

Figure 7: $C X C R 4$ expression correlates positively with worse survival and negatively with $P A T Z 1$ in proneural GBM patients. (A) Overall (OS) and (B) progression-free (PFS) Kaplan-Meier survival curves of the patients shown in Figure 7B-7C (proneural subset of the TCGA dataset of GBM). Note that patients with higher $C X C R 4$ expression have worse survival rates than patients with lower CXCR4, as assessed by log-rank test. (C) YY-plots correlating PATZ1 and CXCR4 expression in the proneural GBMs shown in A and B. Significance of correlation (inbox) was analyzed by Pearson's $\chi^{2}$ test through the R2 web platform (http://r2.amc.nl). (D) VS-GB cells were transiently transfected with $10 \mu \mathrm{g}$ PATZ1 expressing plasmid, and endogenous CXCR4 mRNA was measured 48h later by qRT-PCR. CXCR4 mRNA levels were normalized for endogenous $\beta$-actin levels. The mean $\pm \mathrm{SE}$ of three independent experiments, each in duplicate, is reported. ${ }^{* *}, \mathrm{P}=0.001$. PATZ1 and CXCR4 protein expression is shown on the top by western blot analysis, using vinculin detection as a loading control. Densitometric analysis by Image J software was applied: relative expression levels of CXCR4, compared to empty vector-transfected control and normalized with respect to vinculin, are indicated on the top of the blot. 
finding a significant worse outcome in patients showing absent or low levels of PATZ1 ( $<10 \%$ positive cells), suggesting it may be used as a prognostic marker. Then, extending the analysis to the TCGA dataset, including samples subclassified in the four subtypes described by Verhaak et al. [7], the capacity of PATZ1 to discriminate GBM patients with different prognosis was significantly shown also in the proneural subtype, where low levels of PATZ1 correlate with worse outcome in both overall and progression-free survival curves, independently from other known prognostic factors, such as MGMT promoter methylation and age at diagnosis. Therefore, despite PATZ1 is enriched in the proneural subtype, there are proneural GBMs that express low levels of PATZ1 that are associated with a shorter patients survival. This is consistent with the already described intra-subtype heterogeneity of GBMs, which highlights the importance of finding new markers able to further sub-classify each subtype [35].

Since PATZ1 loss/downregulation has been associated with the acquisition of a mesenchymal phenotype in cancer cells [20], and the mesenchymal phenotype in GBMs is associated with the poorest prognosis and most aggressive phenotype, with advantage in proliferative capacity and neovascularization $[5,38]$, we speculate that a subset of proneural GBMs may be more aggressive due to the downregulation of PATZ1 and consequent activation of a mesenchymal program. Consistent with this hypothesis, we found that in the proneural subset there was a $75 \%$ of negative concordance $(\mathrm{r}=-0.44 ; \mathrm{p}=0.03)$ between PATZ1 and CXCR4, whose overexpression is an outcome common to multiple mechanisms of Epithelial-Mesenchymal Transition (EMT) induction in GBM and directly involved in determining the EMT phenotype [40]. Interestingly, according to the Trafac homology server, the CXCR4 promoter harbors consensus sequence for PATZ1 [33], and Patz1-null mouse embryonic fibroblasts express a 4-fold change increase of Cxcr4 compared to wild-type littermate controls [34]. Therefore, it is possible that PATZ1 could be directly involved in CXCR4 silencing. Indeed, it has been hypothesized that factors associated with the more stem-like phenotype may account for CXCR4 expression in GBM [27], and we provided evidence that PATZ1 could be one of these factors: in VS-GB cells, a primary GBM cell line that does not express endogenous PATZ1, overexpression of PATZ1 leads to downregulation of CXCR4. Further experiments are ongoing in our laboratory to explore the possibility of a direct role of PATZ1 on the CXCR4 promoter in GBM as well as in other cancer-derived cell lines, where PATZ1 appears involved in counteracting EMT. According to current opinions envisaging a parallel between dedifferentiation of cancer cells and reprogramming of somatic cells [41], the transdifferentiation of tumor cells from proneural to mesenchymal may imply a reprogramming process that leads differentiated cells to reacquire the capacity to differentiate into different cells. This is consistent with our previous results showing that PATZ1 plays an inhibitory role in the reprogramming process [34], and suggests a potential PATZ1 inhibitory role on the transition from the proneural to the mesenchymal phenotype. However, further functional experiments are needed to demonstrate the involvement of the PATZ1-CXCR4 axis in the proneural-to-mesenchymal phenotipic switch.

In conclusion, we describe PATZ1 as a novel biomarker of GBM and GSCs, differentially expressed among GBM and GSC subtypes and able to further subdivide the proneural GBM subtype in two populations with different overall and progression free survival. As PATZ1 has been proven an important transcription factor involved in stem cell pluripotency [12], it is encouraging to see that the proneural type of GBM, characterized by a stem-like signature, has higher expression of PATZ1 compared to other types. Finally, this finding may explain the paradox that the proneural type of GBM resists standard therapeutic caused by the cancer stem cells maintained by PATZ1 involved transcription factor networks, while at the same time PATZ1 restricts the proneural type of GBM to differentiation into mesenchymal type.

\section{MATERIALS AND METHODS}

\section{Tissue specimens}

45 patients diagnosed with glioblastoma and 22 with oligodendroglioma were included in the study. They had all undergone a complete excision of the tumor at first surgery. All the cases were identified between 2004 and 2013 and the diagnoses were made in accordance with the 2007 WHO classification [42]. This time interval was chosen in order to ensure a clinical follow-up period of at least 2 years for each identified case. All the cases were reviewed to evaluate adequate representative formalinfixed paraffin-embedded tissue in order to perform immunohistochemical assay. We excluded those cases for which data of outcome were unavailable and for which diagnostic tissue was insufficient. Informed consent for the scientific use of biological material was obtained from all patients and the work has been approved by the local Ethical Committee (CEI 203/15 of 12/11/2015).

\section{Immunohistochemical analysis}

$4 \mu \mathrm{m}$ sections were used for immunohistochemistry. Sections were dewaxed in xylene, hydrated in graded series of alcohol and subjected to heat-induced antigen retrieval. After blocking endogenous peroxidase activity, the tissue was incubated with antibody antiPATZ1 (polyclonal rabbit, R1P1 [22]; 1: 500 dilution, overnight incubation). Subsequently, the slices were rinsed and incubated with the biotinylated secondary 
antibody, at room temperature, for 30 minutes. The bound antibody complexes were stained for 3-5 minutes or until appropriate for microscopic examination with diaminobenzidine, and slides were then counterstained with hematoxylin (30s) and mounted. All slices were reviewed by two experienced pathologists (M.L.D., E.G.).

The assessment of PATZ1 (nuclear) staining was based on the percentage of positive cells: no signal was set as " 0 ", $\leq 10 \%$ as " + ", $>10 \%$ and $<50 \%$ as " ++ " and $\geq 50 \%$ as " +++ ". We defined high expression of PATZ1 as $>10 \%$ of cells staining positive, and low expression as $\leq 10 \%$ of cells staining positive.

\section{Immunofluorescence and confocal microscopy}

For multiple-labeling immunofluorescence, tissues slides were dewaxed, hydrated and antigen retrieval was performed using Dewax and HIER Buffer L (Thermo Fisher Scientific, Cheshire, UK) as previously described [43]. They were incubated with the mixture of two primary antibodies anti-NESTIN (mouse monoclonal, sc23927, Santa Cruz Biotechnology, Santa Cruz, CA; 1:200 dilution, 90 minutes incubation) and anti-PATZ1 (rabbit polyclonal, R1P1; 1: 500 dilution, overnight incubation) or anti PATZ1 and anti-OCT-3/4 (mouse monoclonal, sc-5279 Santa Cruz Biotechnology; 1:100 dilution, 90 minutes incubation) in $1 \%$ BSA in PBS-T in a humified chamber overnight at $4^{\circ} \mathrm{C}$. Fluorescent secondary antibodies, raised against different species (Alexa Fluor 594, with red signal, against rabbit and Alexa Fluor 488, with green signal, against mouse), were used to locate the antigen/primary antibody complexes. Counter staining was made with Hoechst 33258 (nuclear blue staining) present in mounting medium (PBS:Glycerol $=1: 1$ ). Experiments were carried out on an inverted and motorized microscope (Axio Observer Z.1) equipped with a 63x/1.4 Plan-Apochromat objective. The attached laser scanning unit (LSM 700 4x pigtailed laser 405-639, Zeiss, Jena, Germany) enabled confocal imaging. For excitation, $405 \mathrm{~nm}, 488 \mathrm{~nm}$ and $555 \mathrm{~nm}$ lasers were used. Fluorescence emission was revealed by MBS 405/488/555/639 for Hoechst 33258, Alexa Fluor 488 and Alexa Fluor 594. Triple staining immunoflourescence images were acquired separately in the blue, green and red channels at a resolution of $1024 \times 1024$ pixels, with the confocal pinhole set to one Airy unit and then saved in TIFF format.

To assess the stemness of GSCs, NANOG (rabbit polyclonal, ab80892 Abcam; 1:200 dilution), SOX-2 (mouse polyclonal, AB5603 Millipore; 1:500 dilution), OCT-4 (rabbit polyclonal, sc-5279 Santa Cruz; 1:250 dilution) and NESTIN (mouse monoclonal, 92590 Chemicon; 1:100 dilution) expression was evaluated. PATZ1 (rabbit polyclonal, R1P1, 1:500 dilution) expression was analyzed as well. Briefly, cells were fixed in $4 \%$ paraformaldehyde for 20 minutes at room temperature (RT) and permeabilized for 10 minutes at RT with $0.1 \%$ Triton X-100 (Sigma-Aldrich) before exposing them to primary antibodies, that were incubated over-night at $4^{\circ} \mathrm{C}$. Subsequently, Alexa Fluor 488 and Alexa Fluor 555 dyes labeled secondary antibodies against mouse and rabbit, respectively, diluted 1:800 in PBS, were employed for 1 hour in a humidified chamber at $37^{\circ} \mathrm{C}$ (Molecular Probe, Invitrogen). Lastly, slides were mounted using Vectashield (Vector), as mounting medium, added with $0.1 \mu \mathrm{g} / \mathrm{ml}$ DAPI (Sigma) for nuclear staining. Images were acquired utilizing a live cell imaging dedicated system consisting of a Leica DMI 6000B microscope connected to a Leica DFC350FX camera (Leica Microsystems, Wetzlar, Germany) and equipped with a $63 \mathrm{X} / 1.4$ oil immersion objective or a 40X/1.25 oil immersion objective. Adobe Photoshop software was utilized to compose and overlay the images and to adjust contrast.

\section{Cell cultures and transfection}

The independent ethic committee of the Azienda Ospedaliero-Universitaria of Udine has approved the research (Consents 102/2011/Sper and 196/2014/Em). Informed written consents were obtained from patients and all clinical investigations have been conducted according to the principles expressed in the Declaration of Helsinki.

GSCs $(n=11)$ were isolated as previously described $[44,45]$. Briefly, human GBM samples were mechanicallyenzymatically dissociated and cells less than $40 \mu \mathrm{m}$ in diameter cultured on laminin-coated dishes in a growing medium composed as follows: Neurobasal-A medium (Gibco by Invitrogen, Carlsbad, CA), 2mM L-glutamine (Sigma-Aldrich, St. Louis, MO,), 1X N2 supplement (Gibco by Invitrogen), 25mg/ml Insulin, Penicillinstreptomycin, $100 \mathrm{mg} / \mathrm{ml}$ human apo-trasferrin (SigmaAldrich), 1X B-27 supplement (Gibco by Invitrogen), $20 \mathrm{ng} / \mathrm{ml}$ recombinant human basic fibroblast growth factor (h-FGF-basic) (Peprotech, Rocky Hill, NJ), 20 ng/ $\mathrm{ml}$ human epidermal growth factor (h-EGF) (Peprotech). Then cells were cultured in an incubator at $37^{\circ} \mathrm{C}$, $5 \% \mathrm{O} 2 / 5 \% \mathrm{CO} 2$ and analyzed at the third passage in culture. From six GBM samples we isolated, in addition to GSCs, the matched non-stem tumor cells by growing dissociated cells in DMEM (Gibco by Invitrogen) supplemented with $10 \%$ fetal bovine serum (FBS) (EuroClone, Pero, Italy) and $100 \mathrm{U} / \mathrm{ml}$ Penicillin $100 \mu \mathrm{g} / \mathrm{ml} \mathrm{Streptomycin.} \mathrm{Cells}$ were grown in an incubator at $37^{\circ} \mathrm{C}, 5 \% \mathrm{O} 2 / 5 \% \mathrm{CO} 2$ and analyzed at the first passage in culture.

Human GBM U87MG (American Type Culture Collection, ATCC no. HTB-14), were grown in Dulbecco's modified Eagle medium (DMEM) supplemented with 10\% FBS. To obtain tumorspheres, U87MG cells were grown at low density (2000 cells/ml) in Stem cell medium (SM) [DMEM-F12 supplemented with 1\% B27 (Sigma-Aldrich), $10 \mathrm{ng} / \mathrm{ml} \mathrm{h}-\mathrm{FGF}$ (Sigma-Aldrich) and $20 \mathrm{ng} / \mathrm{ml} \mathrm{h-EGF}$ (Sigma-Aldrich)] for 12 days. U87MG tumorspheres were induced to differentiate through the addiction of $10 \%$ FBS in SM medium. The cancer stem cell phenotype of these 
cells was confirmed by assessing the expression of the stemness markers PDGFRß, NANOG and SOX-2.

VS-GB primary cell culture was derived from GBM specimens and grown as described previously [46]. They were transiently transfected by JetPRIME (Polyplus transfections, Illkirch, France) with $10 \mu \mathrm{g}$ of HA-PATZ1 plasmid encoding for PATZ1 variant 4 or $10 \mu \mathrm{g}$ of the empty vector pCEFL-HA as negative control, according to manufacturer's instruction.

\section{RNA extraction and quantitative real time (qRT)-PCR}

Total RNA from cells was purified by TRIzol (Invitrogen). After digestion of the residual genomic DNA by DNase I (Qiagen, Milano, Italy), RNA was reverse transcribed by SuperScript III cDNA synthesis kit (Invitrogen). cDNA was used to perform qPCR reactions with SYBR Green Master Mix gene expression kit (Biorad, Segrate, Italy) in 96-well plates with a LightCycler 480 system (Roche, Monza, Italy). The PCR conditions were as follow: $95^{\circ} \mathrm{C}$ for 3 minutes; 45 cycles at $95^{\circ} \mathrm{C}$ for 10 seconds, $60^{\circ} \mathrm{C}$ for 20 seconds and $72^{\circ} \mathrm{C}$ for 60 seconds. Primer pairs used (300 nm each) were as follows: PATZ1 (5'-TACATCTGCCAGAGCTGTGG3'/5'-TGCACCTGCTTGATATGTCC-3'); GAPDH (5'GTCTCCTCTGACTTCAACAGCG-3'/5'-ACCACCCTG TTGCTGTAGCCAA-3'). CXCR4 (5'-TGAGAAG CATGACGGACAAG-3'/5'-AGGGAAGCGTGATGAC AAAG-3'); $\quad \beta$-ACTIN $\quad\left(5^{\prime}\right.$-CAAGAGATGGCCAC GGCTGCT-3'/5'-TCCTTCTGCATCCTGTCGGCA-3'). Gene expression changes were calculated using the 2(-Delta Delta C(T)) method [47].

\section{Protein extraction and western blot analysis}

Cells were lysed in buffer containing $1 \%$ Nonidet P-40, 1 mmol/liter EDTA, 50 mmol/liter Tris-HCl (pH 7.5), and $150 \mathrm{mmol} /$ liter $\mathrm{NaCl}$ supplemented with Complete protease inhibitors (Roche). Total proteins were resolved in a $10-12 \%$ polyacrylamide gel under denaturing conditions and transferred to nitrocellulose filters for Western blot analyses. Membranes were blocked with 5\% BSA in TBS and incubated with the primary antibodies. Membranes were then incubated with the horseradish peroxidase-conjugated secondary antibody (1:3.000) and the reaction was detected with a Western blotting detection system (enhanced chemiluminescence; GE Healthcare). The primary antibodies used were: anti-PATZ1 [22]; anti-NESTIN (sc23927, Santa Cruz Biotechnology, Santa Cruz, CA); antiPDGFR $\beta$ (3169, Cell Signaling Technology, Boston, MA); anti-NANOG (sc-134218, Santa Cruz Biotechnology); antiSOX2 (sc-20088, Santa Cruz Biotechnology); anti-CXCR4 (C8727, Sigma-Aldrich). To ascertain that equal amounts of protein were loaded, the membranes were incubated with anti-ACTIN (sc-1616-R, Santa Cruz Biotechnology) or anti-VINCULIN (sc-7649, Santa Cruz Biotechnology) antibodies.

\section{Data mining}

For PATZ1 mRNA expression analysis and correlation with clinical, molecular and cell phenotype, the Genomics Analysis and Visualization platform (http://r2.amc.nl) was used with the following datasets: 1) GSE9385 [25], including 6 adult non diseased brain, 26 glioblastomas and 21 oligodendrogliomas,; 2) GSE8049 [26], including 9 different glioblastoma-derived neurosphere cultures in two biological replicates; 3) GSE15209 [28], including stem cells derived from 7 GBMs, 2 oligoastrocytomas, 5 normal fetuses and primary biopsies from 6 normal brains; 4) GSE18015 [29], including 8 gliomas sorted for CD133 expression; 5) the TCGA dataset Tumor Glioblastoma 540 - MAS5.0 - u133a ( $\mathrm{n}=540)$ (http://cancergenome.nih. gov), including 85 samples sub-classified in classical $(\mathrm{n}=$ $17)$, mesenchymal $(\mathrm{n}=27)$, neural $(\mathrm{n}=17)$ and proneural $(\mathrm{n}=24)$ GBM [7], to correlate PATZ1 expression to GBM subtype and specific gene signatures. The last dataset was also used for Overall and Progression-free survival analysis using the scan cut-off mode based on median PATZ1 expression and specifying the proneural track subset.

\section{Statistical analysis and Kaplan-Meier survival curves}

The Fisher's exact test was used to evaluate the correlations between PATZ1 score and the clinical variables (age, gender, site, oligodendroglioma grading).

All correlations within the TCGA and other public datasets were assessed by Pearson's $\chi^{2}$ test or one-way analysis of variance (ANOVA), through the R2 platform (http://r2.amc.nl).

Kaplan-Meier survival curves were used to analyze OS and PFS, and statistical significance was assessed by the log-rank test. In Figure 6A, the stratification of High/Low PATZ1 was based on the percentage of cells expressing nuclear PATZ1 protein by immunohistochemistry (High: $>10 \%$; Low: $<10 \%$ ). The stratification of High/Low PATZ1 and High/Low CXCR4 in the TCGA dataset was based on RNA expression using a cutoff of 100.6 and 197.7 , according to the scan function of the R2 platform used, where an optimum survival cutoff is established based on statistical testing (log-rank test).

PATZ1 expression on human derived stem cells was expressed as mean \pm standard deviation. Comparisons between two groups were performed by paired or unpaired t test, as appropriate.

All statistical analyses were performed using GraphPad Prism 5 software (GraphPad Software, La Jolla, CA). A probability (p) value less than 0.05 was considered statistically significant. 


\section{Abbreviations}

GBM, glioblastoma; GSCs, glioma-initiating stem cells; TCGA, The Cancer Genome Atlas; PATZ1, POZ, AT-hook and zinc-finger 1; OS, overall survival; PFS, progression-free survival; EMT, epithelial-mesenchymal transition; RT, room temperature; h-FGF-basic, human basic fibroblast growth factor; h-EGF, human epidermal growth factor; FBS, fetal bovine serum; DMEM, Dulbecco's modified eagle medium; SM, stem cell medium; IHC, immunohistochemistry.

\section{Author contributions}

Conceived and designed the experiments: M.F. Performed the experiments: E.G., G.B., M.C., G.C. D.C., F.C., M.V., P.F. Contributed materials: P.C. Analyzed the data and discussed the results: M.F., M.L.D., D.C., E.C., C.A., L.C., S.C. Wrote the manuscript: M.F., M.L.D. and D.C. All authors gave approval to the final version of the manuscript.

\section{ACKNOWLEDGMENTS}

We thank the Associazione Italiana Ricerca sul Cancro (AIRC) IG5728 (M.F.), the Association for International Cancer Research (AICR) No 11-0075 (L.C.) and Project ERC- 7FP SP 2 IDEAS QUIDPROQUO G.A. n. 269051 (D.C.) for their support. We are grateful to Michela Bulfoni, Fabiana Franchini and Lisa Agnello for their contribute in some experimental points, and to Antonella Zannetti and Stefania Scala for sharing critical CXCR4 reagents.

\section{CONFLICTS OF INTEREST}

No conflict of interests to declare.

\section{FUNDING}

This research has been supported by the IEOS-CNR, project SV.P15.001.002. It did not receive any specific grant from any funding agency in the public, commercial or not-for-profit sector.

\section{REFERENCES}

1. Louis DN, Perry A, Reifenberger G, von Deimling A, Figarella-Branger D, Cavenee WK, Ohgaki H, Wiestler OD, Kleihues P, Ellison DW. The 2016 World Health Organization of tumours of the central nervous system: a summary. Acta Neuropathol. 2016; 131:803-820.

2. Stupp R, Hegi ME, Mason WP, van den Bent MJ, Taphoorn MJ, Janzer RC, Ludwin SK, Allgeier A, Fisher B, Belanger K, Hau P, Brandes AA, Gijtenbeek J, Marosi C, et al. Effects of radiotherapy with concomitant and adjuvant temozolomide versus radiotherapy alone on survival in glioblastoma in a randomised phase III study: 5-year analysis of the EORTC-NCIC trial. Lancet Oncol. 2009; 10:459-466.

3. Singh SK, Hawkins C, Clarke ID, Squire JA, Bayani J, Hide T, Henkelman RM, Cusimano MD, Dirks PB. Identification of human brain tumour initiating cells. Nature. 2004; 432:396-401.

4. Bleau AM, Huse JT, Holland EC. The ABCG2 resistance network of glioblastoma. Cell Cycle. 2009; 8:2936-2944.

5. Phillips HS, Kharbanda S, Chen R, Forrest WF, Soriano RH, Wu TD, Misra A, Nigro JM, Colman H, Soroceanu L, Williams PM, Modrusan Z, Feuerstein BG, et al. Molecular subclasses of high-grade glioma predict prognosis, delineate a pattern of disease progression, and resemble stages in neurogenesis. Cancer Cell. 2006; 9:157-173.

6. Cancer Genome Atlas Research Network. Comprehensive genomic characterization defines human glioblastoma genes and core pathways. Nature. 2008; 455:1061-1068.

7. Verhaak RG, Hoadley KA, Purdom E, Wang V, Qi Y, Wilkerson MD, Miller CR, Ding L, Golub T, Mesirov JP, Alexe G, Lawrence M, O'Kelly M, et al. Integrated genomic analysis identifies clinically relevant subtypes of glioblastoma characterized by abnormalities in PDGFRA, IDH1, EGFR, and NF1. Cancer Cell. 2010; 17:98-110.

8. Marziali G, Signore M, Buccarelli M, Grande S, Palma A, Biffoni M, Rosi A, D’Alessandris QG, Martini M, Larocca LM, De Maria R, Pallini R, Ricci-Vitiani L. Metabolic/ proteomic signature defines two glioblastoma subtypes with different clinical outcome. Sci Rep. 2016; 6:21557.

9. Vescovi AL, Galli R, Reynolds BA. Brain tumour stem cells. Nat Rev Cancer. 2006; 6:425-436.

10. Chen J, Li Y, Yu TS, McKay RM, Burns DK, Kernie $\mathrm{SG}$, Parada LF. A restricted cell population propagates glioblastoma growth after chemotherapy. Nature. 2012; 488:522-526.

11. Zhu Z, Khan MA, Weiler M, Blaes J, Jestaedt L, Geibert M, Zou P, Gronych J, Bernhardt O, Korshunov A, Bugner V, Lichter P, Radlwimmer B, et al. Targeting self-renewal in high-grade brain tumors leads to loss of brain tumor stem cells and prolonged survival. Cell Stem Cell. 2014; 15:185-198.

12. Ow JR, Ma H, Jean A, Goh Z, Lee YH, Chong YM, Soong R, Fu XY, Yang H, Wu Q. Patz1 regulates embryonic stem cell identity. Stem Cells Dev. 2014; 23:1062-1073.

13. Valentino T, Palmieri D, Vitiello M, Simeone A, Palma G, Arra C, Chieffi P, Chiariotti L, Fusco A, Fedele M. Embryonic defects and growth alteration in mice with homozygous disruption of the Patzl gene. J Cell Physiol. 2013; 228:646-653.

14. Costoya JA. Functional analysis of the role of POK transcriptional repressors. Brief Funct Genomic Proteomic. 2007; 6:8-18.

15. Cho JH, Kim MJ, Kim KJ, Kim JR. POZ/BTB and AT-hook-containing zinc finger protein 1 (PATZ1) inhibits 
endothelial cell senescence through a p53 dependent pathway. Cell Death Differ. 2012; 19:703-712.

16. Valentino T, Palmieri D, Vitiello M, Pierantoni GM, Fusco A, Fedele M. PATZ1 interacts with $\mathrm{p} 53$ and regulates expression of p53-target genes enhancing apoptosis or cell survival based on the cellular context. Cell Death Dis. 2013; 4:e963.

17. Tritz R, Mueller BM, Hickey MJ, Lin AH, Gomez GG, Hadwiger P, Sah DW, Muldoon L, Neuwelt EA, Kruse CA. siRNA down-regulation of the PATZ1 gene in human glioma cells increases their sensitivity to apoptotic stimuli. Cancer Ther. 2008; 6:865-876.

18. Keskin N, Deniz E, Eryilmaz J, Un M, Batur T, Ersahin T, Cetin Atalay R, Sakaguchi S, Ellmeier W, Erman B. PATZ1 is a DNA damage-responsive transcription factor that inhibits p53 function. Mol Cell Biol. 2015; 35:1741-1753.

19. Tian X, Sun D, Zhang Y, Zhao S, Xiong H, Fang J. Zinc finger protein 278 , a potential oncogene in human colorectal cancer. Acta Biochim Biophys Sin (Shanghai). 2008; 40:289-296.

20. Chiappetta G, Valentino T, Vitiello M, Pasquinelli R, Monaco M, Palma G, Sepe R, Luciano A, Pallante P, Palmieri D, Aiello C, Rea D, Losito SN, et al. PATZ1 acts as a tumor suppressor in thyroid cancer via targeting p53-dependent genes involved in EMT and cell migration. Oncotarget. 2015; 6:5310-5323. https://doi.org/10.18632/ oncotarget.2776.

21. Fedele M, Franco R, Salvatore G, Paronetto MP, Barbagallo F, Pero R, Chiariotti L, Sette C, Tramontano D, Chieffi G, Fusco A, Chieffi P. PATZ1 gene has a critical role in the spermatogenesis and testicular tumours. J Pathol. 2008; 215:39-47.

22. Franco R, Scognamiglio G, Valentino E, Vitiello M, Luciano A, Palma G, Arra C, La Mantia E, Panico L, Tenneriello V, Pinto A, Frigeri F, Capobianco G, et al. PATZ1 expression correlates positively with BAX and negatively with BCL6 and survival in human diffuse large B cell lymphomas. Oncotarget. 2016; 7:59158-59172. https://doi.org/10.18632/ oncotarget.10993.

23. Ho MY, Liang CM, Liang SM. PATZ1 induces PP4R2 to form a negative feedback loop on IKK/NF- $\kappa \mathrm{B}$ signaling in lung cancer. Oncotarget. 2016; 7:52255-52269. https://doi. org/10.18632/oncotarget.10427.

24. Cox JL, Wilder PJ, Gilmore JM, Wuebben EL, Washburn MP, Rizzino A. The SOX2-interactome in brain cancer cells identifies the requirement of MSI2 and USP9X for the growth of brain tumor cells. PLoS One. 2013; 8:e62857.

25. French PJ, Peeters J, Horsman S, Duijm E, Siccama I, van den Bent MJ, Luider TM, Kros JM, van der Spek P, Sillevis Smitt PA. Identification of differentially regulated splice variants and novel exons in glial brain tumors using exon expression arrays. Cancer Res. 2007; 67:5635-5642.

26. Günter HS, Schmidt NO, Phillips HS, Kemming D, Kharbanda S, Soriano R, Modrusan Z, Meissner H, Westphal M, Lamszus K. Glioblastoma-derived stem cell-enriched cultures form distinct subgroups according to molecular and phenotypic criteria. Oncogene. 2008; 27:2897-2909.

27. Schulte A. Gunther HS, Phillips HS, Kemming D, Martens T, Kharbanda S, Soriano RH, Modrusan Z, Zapf S, Westphal M, Lamszus K. A distinct subset of glioma cell lines with stem cell-like properties reflects the transcriptional phenotype of glioblastomas and overexpresses CXCR4 as therapeutic target. Glia. 2011; 59:590-602.

28. Pollard SM, Yoshikawa K, Clarke ID, Danovi D, Stricker S, Russell R, Bayani J, Head R, Lee M, Bernstein M, Squire JA, Smith A, Dirks P. Glioma stem cell lines expanded in adherent culture have tumor-specific phenotypes and are suitable for chemical and genetic screens. Cell Stem Cell. 2009; 4:568-580.

29. Garcia JL, Perez-Caro M, Gomez-Moreta JA, Gonzalez F, Ortiz J, Blanco O, Sancho M, Hernandez-Rivas JM, GonzalezSarmiento R, Sanchez-Martin M. Molecular analysis of ex-vivo CD133+ GBM cells revealed a common invasive and angiogenic profile but different proliferative signatures among high grade gliomas. BMC Cancer. 2010; 10:454.

30. Kim Y, Kim E, Wu Q, Guryanova O, Hitomi M, Lathia JD, Serwanski D, Sloan AE, Weil RJ, Lee J, Nishiyama A, Bao S, Hjelmeland AB, et al. Platelet-derived growth factor receptors differentially inform intertumoral and intratumoral heterogeneity. Genes Dev. 2012; 26:1247-1262.

31. Zhu Y, Yang P, Wang Q, Hu J, Xue J, Li G, Zhang G, Li X, Li W, Zhou C, Zhao M, Wang D. The effect of CXCR4 silencing on epithelial-mesenchymal transition related genes in glioma U87 cells. Anat Rec (Hoboken). 2013; 296:1850-1856.

32. Liu G, Yuan X, Zeng Z, Tunici P, Ng H, Abdulkadir IR, Lu L, Irvin D, Black KL, Yu JS. Analysis of gene expression and chemoresistance of CD133+ cancer stem cells in glioblastoma. Mol Cancer. 2006; 5:67.

33. Jegga AG, Sherwood SP, Carman JW, Pinski AT, Phillips JL, Pestian JP, Aronow BJ. Detection and visualization of compositionally similar cis-regulatory element clusters in orthologous and coordinately controlled genes. Genome Res. 2002; 12:1408-1417.

34. Ma H, Ow JR, Tan BC, Goh Z, Feng B, Loh YH, Fedele M, $\mathrm{Li} \mathrm{H}, \mathrm{Wu}$ Q. The dosage of Patz1 modulates riprogramming process. Sci Rep. 2014; 4:7519.

35. Friedmann-Morvinski D. Glioblastoma heterogeneity and cancer cell plasticity. Crit Rev Oncog. 2014; 19:327-336.

36. Meacham CE, Morrison SJ. Tumour heterogeneity and cancer cell plasticity. Nature. 2013; 501:328-337.

37. Brown DV, Daniel PM, D'Abaco GM, Gogos A, Ng W, Morokoff AP, Mantamadiotis T. Coexpression analysis of CD133 and CD44 identifies proneural and mesenchymal subtypes of glioblastoma multiforme. Oncotarget. 2015; 6:6267-6280. https://doi.org/10.18632/oncotarget.3365.

38. Kim YW, Koul D, Kim SH, Lucio-Eterovic AK, Freire PR, Yao J, Wang J, Almeida JS, Aldape K, Yung WK. 
Identification of prognostic gene signatures of glioblastoma: a study based on TCGA data analysis. Neuro Oncol. 2013; 15:829-839.

39. Vitiello M, Valentino T, De Menna M, Crescenzi E, Francesca P, Rea D, Arra C, Fusco A, De Vita G, Cerchia L, Fedele M. PATZ1 is a target of miR-29b that is induced by Ha-Ras oncogene in rat thyroid cells. Sci Rep. 2016; $6: 25268$.

40. Richardson PJ. CXCR4 and glioblastoma. Anticancer Agents Med Chem. 2016; 16:59-74.

41. Friedmann-Morvinski D, Verma IM. Dedifferentiation and reprogramming: origins of cancer stem cells. EMBO Rep. 2014; 15:244-253.

42. Louis DN, Ohgaki H, Wiestler OD, Cavenee WK, Burger PC, Jouvet A, Scheithauer BW, Kleihues P. The 2007 WHO classification of tumours of the central nervous system. Acta Neuropathol. 2007; 114:97-109.

43. Calì G, Gentile F, Mogavero S, Pallante P, Nitsch R, Ciancia G, Ferraro A, Fusco A, Nitsch L. CDH16/Ksp-cadherin is expressed in the developing thyroid gland and is strongly down-regulated in thyroid carcinomas. Endocrinology. 2012; 153:522-534.
44. Andolfi L, Bourkoula E, Migliorini E, Palma A, Pucer A, Skrap M, Scoles G, Beltrami AP, Cesselli D, Lazzarino M. Investigation of adhesion and mechanical properties of human glioma cells by single cell force spectroscopy and atomic force microscopy. PLoS One. 2014; 9:e112582.

45. Bourkoula E, Mangoni D, Ius T, Pucer A, Isola M, Musiello D, Marzinotto S, Toffoletto B, Sorrentino M, Palma A, Caponnetto F, Gregoraci G, Vindigni M, et al. Gliomaassociated stem cells: a novel class of tumor-supporting cells able to predict prognosis of human low-grade gliomas. Stem Cells. 2014; 32:1239-1253.

46. Camorani S, Esposito CL, Rienzo A, Catuogno S, Iaboni M, Condorelli G, de Franciscis V, Cerchia L. Inhibition of receptor signaling and of glioblastoma-derived tumor growth by a novel PDGFR $\beta$ aptamer. Mol Ther. 2014; 22:828-841.

47. Livak KJ, Schmittgen TD. Analysis of relative gene expression data using real-time quantitative PCR and the 2(-Delta Delta C(T)) method. Methods. 2001; 25:402-408. 